\title{
A POT1 mutation implicates defective telomere end fill-in and telomere truncations in Coats plus
}

\author{
Hiroyuki Takai, ${ }^{1,8}$ Emma Jenkinson, ${ }^{2,8}$ Shaheen Kabir, ${ }^{1}$ Riyana Babul-Hirji, ${ }^{3}$ Nasrin Najm-Tehrani, ${ }^{4}$ \\ David A. Chitayat, ${ }^{5,6}$ Yanick J. Crow, ${ }^{2,7,9}$ and Titia de Lange ${ }^{1,9}$ \\ ${ }^{1}$ The Rockefeller University, New York, New York 10065, USA; ${ }^{2}$ Manchester Centre for Genomic Medicine, Institute of Human \\ Development, Faculty of Medical and Human Sciences, Manchester Academic Health Sciences Centre, University of Manchester, \\ Manchester M13 9PT, United Kingdom; ${ }^{3}$ Department of Pediatrics, Division of Clinical and Metabolic Genetics, The Hospital for \\ Sick Children, University of Toronto, Toronto, Ontario M5G 1Z5, Canada; ${ }^{4}$ Department of Pediatrics, Division of Opthalmology \\ and Visions Sciences, The Hospital for Sick Children, University of Toronto, Toronto, Ontario M5G 1Z5, Canada; ${ }^{5}$ The Prenatal \\ Diagnosis and Medical Genetics Program, Department of Obstetrics and Gynecology, Mount Sinai Hospital, University of Toronto, \\ Toronto, Ontario M5G 1X5, Canada; ${ }^{6}$ Department of Paediatrics, Division of Clinical and Metabolic Genetics, The Hospital for \\ Sick Children, University of Toronto, Toronto, Ontario M5G 1Z5, Canada; ${ }^{7}$ UMR 1163, Institut National de la Santé et de la \\ Recherche Médicale, Laboratory of Neurogenetics and Neuroinflammation, Paris Descartes-Sorbonne Paris Cité University, \\ Institut Imagine, Hôpital Necker, Paris 75015, France
}

Coats plus (CP) can be caused by mutations in the CTC1 component of CST, which promotes polymerase a (pola)/ primase-dependent fill-in throughout the genome and at telomeres. The cellular pathology relating to $\mathrm{CP}$ has not been established. We identified a homozygous POT1 S322L substitution $\left(\mathrm{POT} 1^{\mathrm{CP}}\right)$ in two siblings with CP. POT1 ${ }^{\mathrm{CP}}$ induced a proliferative arrest that could be bypassed by telomerase. POT1 ${ }^{\mathrm{CP}}$ was expressed at normal levels, bound TPP1 and telomeres, and blocked ATR signaling. POT1 ${ }^{\mathrm{CP}}$ was defective in regulating telomerase, leading to telomere elongation rather than the telomere shortening observed in other telomeropathies. POT1 ${ }^{\mathrm{CP}}$ was also defective in the maintenance of the telomeric $\mathrm{C}$ strand, causing extended 3' overhangs and stochastic telomere truncations that could be healed by telomerase. Consistent with shortening of the telomeric $\mathrm{C}$ strand, metaphase chromosomes showed loss of telomeres synthesized by leading strand DNA synthesis. We propose that $\mathrm{CP}$ is caused by a defect in POT1/CST-dependent telomere fill-in. We further propose that deficiency in the fill-in step generates truncated telomeres that halt proliferation in cells lacking telomerase, whereas, in tissues expressing telomerase (e.g., bone marrow), the truncations are healed. The proposed etiology can explain why CP presents with features distinct from those associated with telomerase defects (e.g., dyskeratosis congenita).

[Keywords: CST; CTC1; Coats plus; Exo1; POT1; telomerase; telomere]

Supplemental material is available for this article.

Received December 21, 2015; revised version accepted March 2, 2016.

Coats plus $(\mathrm{CP})$ is a rare autosomal recessive disorder, the key characteristics of which include retinal telangiectasia and exudates (Coats disease); intracranial calcification with leukodystrophy and cysts; osteopenia with tendency to fracture and poor bone healing; and a high risk of developing vasculature ectasias in the stomach, small intestine, and liver, leading to gastrointestinal bleeding and portal hypertension (Tolmie et al. 1988; Crow et al. 2004; Linnankivi et al. 2006; Briggs et al. 2008).

Recently, CP was shown to be due to biallelic mutations in CTC1, encoding conserved telomere mainte-

\footnotetext{
${ }^{8}$ These authors contributed equally to this work.

${ }^{9}$ These authors contributed equally to this work.

Corresponding authors: delange@rockefeller.edu, yanickcrow@mac.com Article published online ahead of print. Article and publication date are online at http://www.genesdev.org/cgi/doi/10.1101/gad.276873.115.
}

nance component 1 (Anderson et al. 2012; Polvi et al. 2012; Walne et al. 2013). CTC1 is distantly related to the budding yeast telomeric protein Cdc13 and, like Cdc13, interacts with STN1 and TEN1 to form the three-subunit CST complex (for review, see Price et al. 2010; Chen and Lingner 2013).

The mammalian CST complex contributes to telomere function in three ways. First, CST is required to regenerate the proper telomeric $3^{\prime}$ overhang after the replication of telomere ends (Miyake et al. 2009; Surovtseva et al. 2009; Wang et al. 2012; Wu et al. 2012), most likely by

(C) 2016 Takai et al. This article is distributed exclusively by Cold Spring Harbor Laboratory Press for the first six months after the full-issue publication date (see http://genesdev.cshlp.org/site/misc/terms.xhtml). After six months, it is available under a Creative Commons License (Attribution-NonCommercial 4.0 International), as described at http://creativecommons.org/licenses/by-nc/4.0/. 
facilitating a fill-in step that regenerates $3^{\prime}$ overhangs of the correct size after extensive nucleolytic degradation of the $5^{\prime}$ ended C-rich telomeric repeat strand. In mice, CST is recruited to telomeres by one of the two mouse POT1 proteins, POT1b, which is the component of shelterin that governs the length of the $3^{\prime}$ overhang (Hockemeyer et al. 2006, 2008; He et al. 2009; Wu et al. 2012). Human telomeres contain a single POT1 protein, which is thought to bind CST indirectly via its binding partner, TPP1, although a direct interaction of POT1 with CST has also been reported (Wan et al. 2009; Chen et al. 2012; Diotti et al. 2014).

Second, CST plays a role in the negative regulation of telomerase (Chen et al. 2012). Thus, when CST is inhibited in certain human lines (Wan et al. 2009; Chen et al. 2012; Kasbek et al. 2013), telomere length homeostasis is reset to a longer length. CST can inhibit telomerase in vitro, presumably in part through its ability to bind to the TTAGGG repeat telomerase primers (Chen et al. 2012). However, in vivo, the fill-in reaction itself may also contribute to the negative regulation of telomerase, since mouse cells harboring a temperature-sensitive polymerase $\alpha($ pola) have elongated telomeres at elevated temperature (Nakamura et al. 2005), as do human cells in which pola is partially inhibited with aphidicolin (Sfeir et al. 2009). Of note, POT1 is also a negative regulator of telomerase (Loayza and de Lange 2003; Liu et al. 2004; Ye et al. 2004), potentially acting through occlusion of the $3^{\prime}$ end of the telomere (Lei et al. 2004; Kelleher et al. 2005) and/or mechanisms involving CST.

A third function of CST is to facilitate the replication of the duplex telomeric TTAGGG repeat array (Surovtseva et al. 2009; Gu et al. 2012; Stewart et al. 2012; Wang et al. 2012; Bryan et al. 2013; Chen et al. 2013; Kasbek et al. 2013), which poses a challenge for the replisome (Sfeir et al. 2009). Frequent stalling of the replication fork, in part due to the formation of G4 DNA in the TTAGGG repeat template of lagging strand DNA synthesis (Zimmermann et al. 2014), is thought to result in single-stranded gaps that require CST-mediated fill-in. When the single-stranded gaps are not repaired, telomeres exhibit aberrant structures in metaphase-referred to as fragile telomeres (Martínez et al. 2009; Sfeir et al. 2009) - that resemble the common fragile sites.

The functions of CST are consistent with biochemical data on the ability of CST to associate with DNA pola/ primase and promote DNA replication /Goulian et al. 1990; Casteel et al. 2009; Nakaoka et al. 2012; Diotti et al. 2014) and the proposal that CST is a specialized form of RPA (Gao et al. 2007). Indeed, human CST was first identified as a pola/primase-associated factor (AAF) (Goulian et al. 1990; Casteel et al. 2009). Recent data confirm the view that mammalian CST is involved in some aspects of genome-wide DNA replication (Gu et al. 2012; Stewart et al. 2012; Kasbek et al. 2013). Budding yeast CST also interacts with pola (Qi and Zakian 2000; Grossi et al. 2004) and has long been known to counteract nucleolytic attack at telomere ends (Weinert and Hartwell 1993; Garvik et al. 1995; Grandin et al. 1997; Zubko et al. 2004).
Here we describe two siblings demonstrating a clinical and radiological phenotype consistent with $\mathrm{CP}$ in whom mutations in CTC1 were not present, suggesting the possibility of genetic heterogeneity. Of note, sequencing of STN1 and TEN1 was also normal. Rather, we identified a homozygous variant in the POT1 gene /referred to here as $\mathrm{POT} 1^{\mathrm{CP}}$ ) and describe the effect of this mutation on telomere structure and function. POT1 is the ssDNAbinding protein in shelterin (Baumann and Cech 2001; Lei et al. 2004). Human POT1 was previously implicated in protecting telomeres from ATR-mediated DNA damage signaling, the regulation of the $3^{\prime}$ overhang and the sequence of the $5^{\prime}$ end of telomeres, and the negative regulation of telomere length maintenance by telomerase (for review, see Palm and de Lange 2008). We show that $\mathrm{POT} 1^{\mathrm{CP}}$ is a separation-of-function allele that causes a defect in the maintenance of the $\mathrm{C}$ strand of telomeres and induces stochastic telomere truncations that lead to proliferative arrest. The CP-associated telomere truncations and accompanying arrest can be repressed by expression of telomerase. We propose that $\mathrm{CP}$ mutations in either POT1 or CTC1 cause incomplete fill-in of the Crich telomeric strand after DNA replication, resulting in telomere truncations that are the proximal cause of the disease.

\section{Results}

\section{A novel homozygous POT1 mutation in two related patients}

The parents of patients F339:II:1 and F339:II:2 are third cousins and have three children-two affected females and an unaffected male sibling (Fig. 1A). These patients have been previously reported as demonstrating classical features of CP (Fig. 1A; Briggs et al. 2008; Anderson et al. 2012), although a possibly noteworthy feature in this family has been the very early onset and rapid progression of the disease when compared with other affected individuals. The older sibling (F339:II:1) demonstrated a prenatal onset and died of gastrointestinal bleeding at 3 yr of age. Meanwhile, her younger sibling (F339:II:2) began to deteriorate rapidly at age $4 \mathrm{yr}$ and currently, at age $7 \mathrm{yr}$, is incontinent, unable to walk or talk, and has difficulty feeding.

In view of the consanguineous relationship of the parents in this family, we undertook genome-wide single nucleotide polymorphism (SNP) microarray analysis and autozygosity mapping using AutoSNPa software. The two affected individuals were heterozygous across the chromosomal interval containing CTC1 (Briggs et al. 2008). A 13.7-Mb region of shared homozygosity was identified on chromosome 7q31.32-q33 (Fig. 1B). The region was flanked by SNPs rs 12668266 (position 123,614,938) and rs270898 (position 137,362,637) (build hg19). This locus contains 76 known RefSeq genes, one of which is POT1, encoding the telomeric POT1 protein.

The sequence of the POT1 gene was determined using PCR products generated with primers designed to amplify all coding exons and exon/intron boundaries. A novel 
A

\begin{tabular}{lcccccccc}
\hline $\begin{array}{l}\text { Patient/ } \\
\text { gender }\end{array}$ & $\begin{array}{l}\text { Age/ } \\
\text { (age at } \\
\text { death) }\end{array}$ & IUGR & ICC & LE & $\begin{array}{c}\text { RE } \\
\text { (age at } \\
\text { diagnosis } \\
\text { in months) }\end{array}$ & $\begin{array}{c}\text { Hair/ } \\
\text { skin/ } \\
\text { nail } \\
\text { change }\end{array}$ & $\begin{array}{c}\text { Fractures } \\
\text { (age of } \\
\text { onset in }\end{array}$ & $\begin{array}{c}\text { Gl ectasias } \\
\text { (age of onset } \\
\text { in years) }\end{array}$ \\
\hline $\begin{array}{l}\text { F339:Il:1 } \\
\text { female }\end{array}$ & (3 yr) & Yes & Yes & Yes & Yes (1.5) & No & Yes (3) & Yes (3) \\
$\begin{array}{l}\text { F339:Il:2 } \\
\text { female }\end{array}$ & $7 \mathrm{yr}$ & Yes & Yes & Yes & Yes (1.5) & Yes* & No & No \\
\hline
\end{tabular}

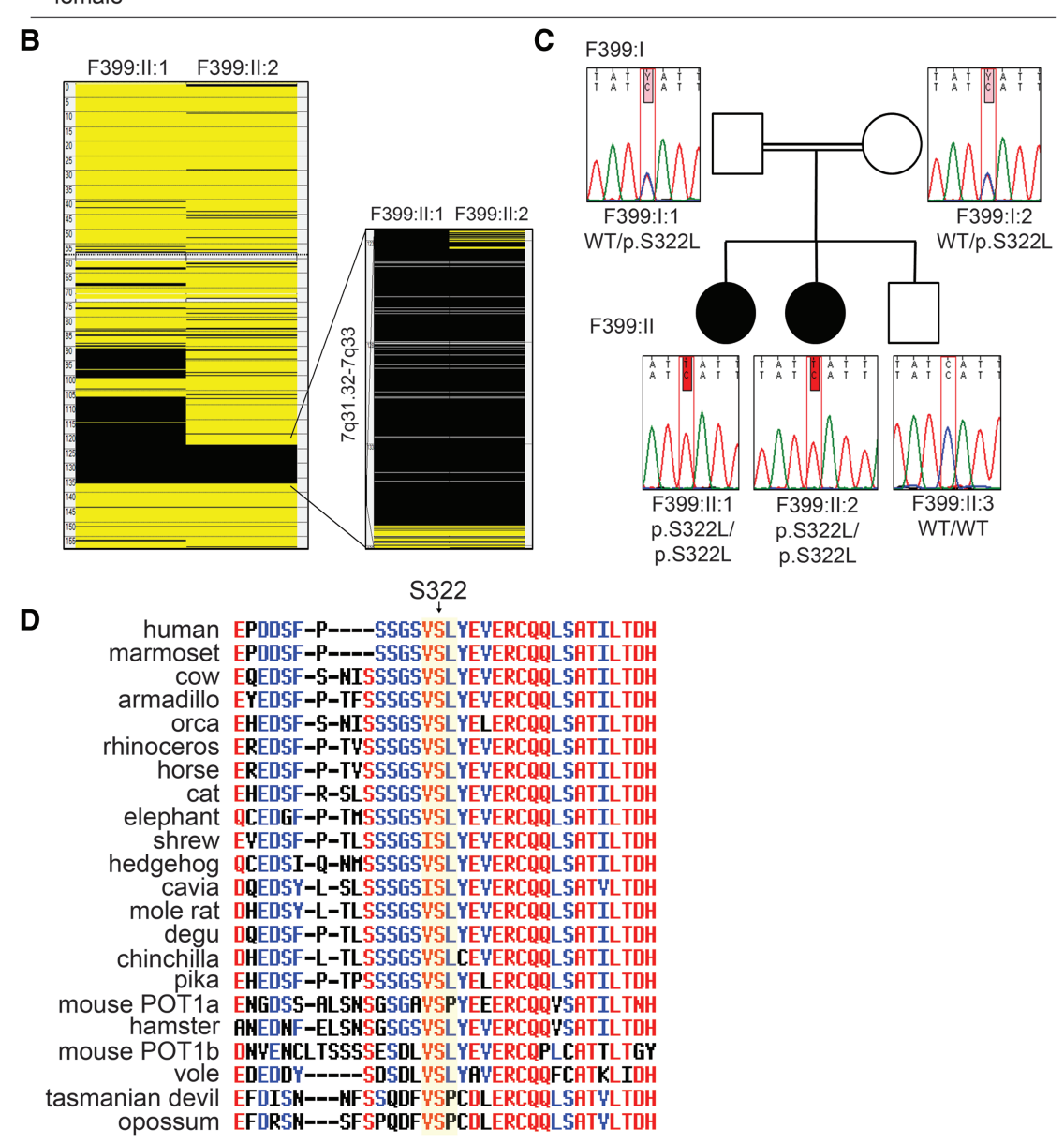

Figure 1. Two patients with a phenotype conforming to $\mathrm{CP}$ with a homozygous S322L substitution in POT1. (A) Clinical features of the affected siblings in family F339. (IUGR) Intrauterine growth retardation; (ICC) intracranial calcification in a distribution typical of $\mathrm{CP}$; (LE) leukoencephalopathy; (RE) retinal exudates typical of $\left.\mathrm{CP} ;{ }^{*}\right)$ sparse hair. (B) Region of homozygosity on chromosome 7 common to the two affected siblings from consanguineous family F339. Black and yellow bars indicate homozygous and heterozygous single nucleotide polymorphisms (SNPs), respectively. Isolated heterozygous SNPs within larger homozygous segments are likely to represent miscalls. Information was derived from AutoSNPa. (C) Pedigree of family F339 showing POT1 sequence chromatograms and protein status. (WT) Wild type; (closed shapes) clinically affected individuals; (open shapes) unaffected individuals. The top text above the sequence traces indicates sequencing reads, and the bottom text indicates the POT1 reference sequence. (Pink boxes) Heterozygous variants; (red boxes) homozygous variants. $(D)$ Conservation of S322 in mammalian POT1. Sequences from the indicated mammalian POT1 proteins were aligned using ClustalW using the MultAlin interface (http://multalin. toulouse.inra.fr/multalin). homozygous missense variant, c.965C $>\mathrm{T}$ [Chr7(GRCh3) 7:g.124487037G $>$ A;p.S322L], was identified in both affected individuals (Fig. 1C). Both parents were heterozygous carriers of the p.S322L change, while the unaffected male sibling demonstrated the wild-type POT1 sequence on both alleles (Fig. 1C). The p.S322L variant was not seen in the 61,486 unrelated individuals present on the Exome Aggregation Consortium (ExAC) browser (http ://exac.broadinstitute.org, December 18, 2014, version) and was not annotated as a polymorphism in dbSNP. S322 is a highly conserved residue across mammalian POT1 proteins (Fig. 1D), and the S322L change is predicted as pathogenic according to in silico prediction software packages Polyphen2 (probably damaging 0.959) and SIFT (deleterious; score 0, median 3.87). S322 is beyond the DNA-binding domain of human POT1, in a region of unknown function and structure (Lei et al. 2004). However, the CP-associated variant at S322 is noteworthy in that a mutation in the leucine neighboring the equivalent ser- ine in mouse POT1b diminishes its interaction with CST (Wu et al. 2012).

\section{$P O T 1^{C P}$ cells show premature senescence and contain dysfunctional telomeres}

Patient-derived POT1 ${ }^{\mathrm{CP}}$ fibroblasts were cultured in parallel with fibroblasts from a normal individual and from another CP patient with two mutated CTC1 alleles (K242Lfs*41 |G503R, a combination referred to here as $\mathrm{CTC}^{\mathrm{CP}}$ ). Both POT1 ${ }^{\mathrm{CP}}$ and $\mathrm{CTC} 1^{\mathrm{CP}}$ fibroblasts rapidly entered senescence, whereas normal fibroblasts could be cultured for a greater number of population doublings (PDs) (Fig. 2A; Supplemental Fig. S1). Even when infected with a retrovirus expressing SV40 large T antigen (SV40$\mathrm{LT}$ ), which inactivates the $\mathrm{Rb}$ and $\mathrm{p} 53$ pathways, $\mathrm{POT} 1^{\mathrm{CP}}$ and $\mathrm{CTCl}^{\mathrm{CP}}$ fibroblasts divided only a limited number of times (10-15 PDs) (Fig. 2B), indicating a severe proliferation defect reminiscent of telomere crisis. 
A

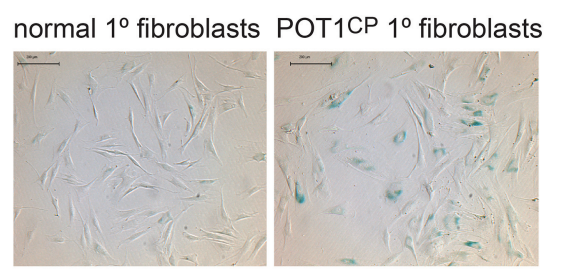

E

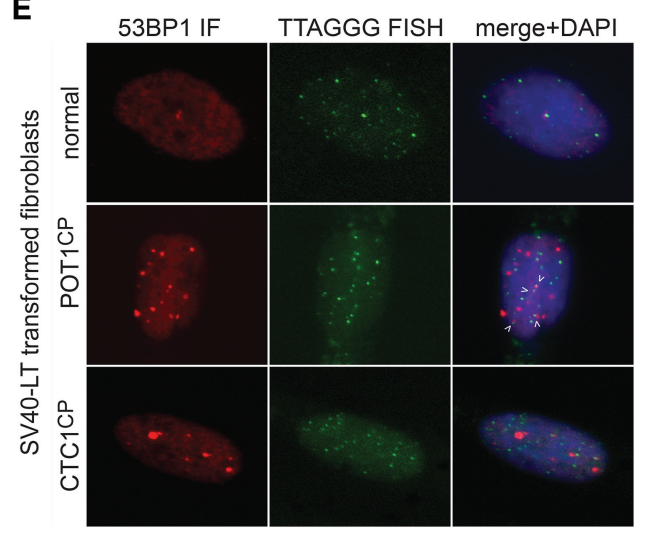

$\mathbf{F}$

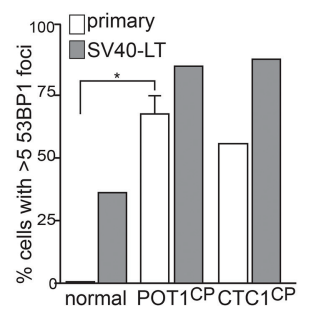

B

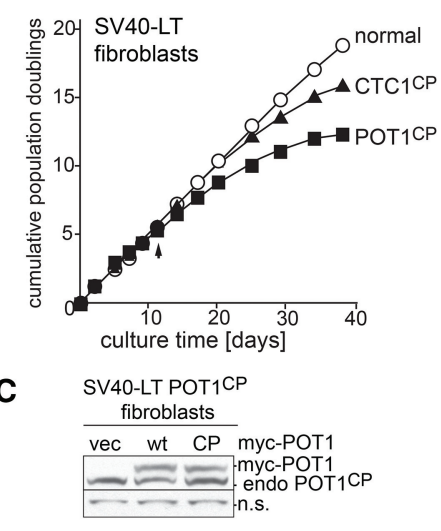

D

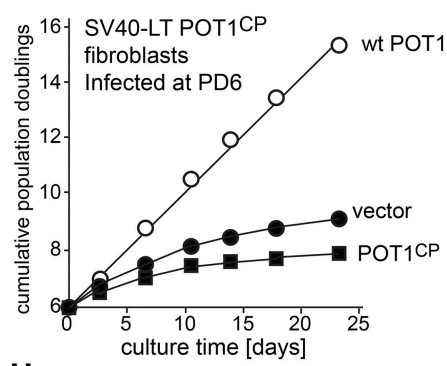

H

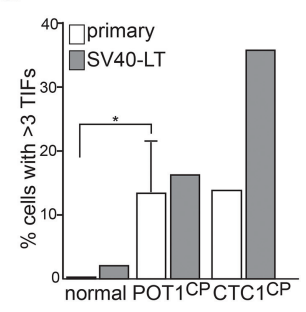

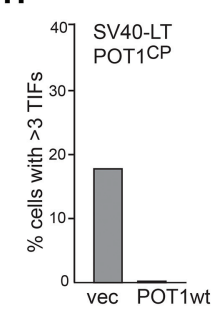

Figure 2. $\mathrm{POT} 1^{\mathrm{CP}}$ cells have a proliferation defect and harbor dysfunctional telomeres. (A) Phase contrast microscopic images of normal primary fibroblasts and POT ${ }^{\mathrm{CP}}$ fibroblasts. Cells were grown in parallel and stained for the senescence-associated $\beta$-galactosidase marker. (B) Graph representing the proliferation of the indicated SV40-LT transformed fibroblasts. (Closed squares) POT1 ${ }^{\mathrm{CP}}$ fibroblasts; (closed triangles) $\mathrm{CTC1}^{\mathrm{CP}}$ fibroblasts; (open circles) normal fibroblasts. (C) Immunoblot for POT1 in SV40-LT transformed POT ${ }^{\mathrm{CP}}$ fibroblasts complemented with myc-tagged wild-type (wt) POT1 or POT1 ${ }^{\mathrm{CP}}$. (n.s.) Nonspecific band serving as loading control. $(D)$ Graph representing the proliferation of SV40-LT transformed POT $1^{\mathrm{CP}}$ fibroblasts after retroviral transduction of wild-type POT1 (open circles), POT $1^{\mathrm{CP}}$ (closed squares), or the empty retroviral vector (closed circles) at $\mathrm{PD} 6$ in $B$ (arrow). (E) 53BP1 foci at telomeres in POT1 $1^{\mathrm{CP}}$ and $\mathrm{CTC1}^{\mathrm{CP}}$ cells. SV40-LT transformed fibroblasts were analyzed by immunofluorescence (IF) for 53BP1 (red) and FISH for telomeric DNA (green). 53BP1 foci at telomeres are highlighted with arrowheads. $(F, G)$ Quantification of the fibroblasts with five or more 53BP1 foci $(F)$ or three or more 53BP1 foci colocalizing with telomeres $(G)$ in the indicated cells, determined as shown in $E$. Where applicable, mean values and SDs are shown. $\left({ }^{*}\right) P<$ 0.05 , unpaired $t$-test. $(H)$ Quantification of three or more 53BP1 foci colocalizing with telomeres in SV40-LT transformed POT $1^{\mathrm{CP}}$ fibroblasts transduced with wild-type POT1 or vector as shown in $D$.
The proliferation defect of SV40-LT transformed POT $1{ }^{\mathrm{CP}}$ cells could be rescued by expression of exogenous wild-type POT1 but not by POT $1^{\mathrm{CP}}$, indicating that the POT1 mutation is the cause of the diminished proliferative potential (Fig. 2C,D) and of the CP phenotype exhibited by these patients.

Immunofluorescence (IF) for the DNA damage response factor 53BP1 in combination with telomeric FISH showed that primary and SV40-LT transformed POT1 ${ }^{\mathrm{CP}}$ cells contained telomere dysfunction-induced foci (TIFs) (Fig. 2E-G), which are indicative of a DNA damage signal at telomeres (Takai et al. 2003). The TIF phenotype was repressed by expression of wild-type POT1 (Fig. 2H). Similarly, CTC1 ${ }^{\mathrm{CP}}$ cells demonstrated evidence of telomere dysfunction (Fig. 2E-G). POT $1^{\mathrm{CP}}$ and $\mathrm{CTC} 1^{\mathrm{CP}}$ cells also showed 53BP1 foci that did not obviously colocalize with telomeric signals (Fig. 2E-G). An explanation for this phenomenon is given below.

The growth arrest associated with POT $1{ }^{\mathrm{CP}}$ and $\mathrm{CTC} 1^{\mathrm{CP}}$ could be mitigated by activation of telomerase achieved through lentiviral introduction of hTERT. After the introduction of hTERT into the SV40-LT transformed CP fibroblasts, numerous $(>50)$ immortal clones that carried the
CP mutations in POT1 or CTC1 were isolated (see below), whereas no clones emerged from cells infected in parallel with the vector control.

\section{POT1 ${ }^{C P}$ binds TPP1 and telomeres and represses ATR signaling}

Immunoblotting showed that the expression of POT1 in the primary POT $1{ }^{\mathrm{CP}}$ fibroblasts was indistinguishable from that of normal fibroblasts (Fig. 3A). Furthermore, POT $1^{\mathrm{CP}}$ showed the expected interaction with TPP1 when cotransfected into $293 \mathrm{~T}$ cells, whereas a version of POT1 lacking the C-terminal TPP1-interacting domain did not (Fig. 3B). Consistent with its interaction with TPP1, IF in combination with telomeric FISH showed that a myc-tagged version of POT $1^{\mathrm{CP}}$ localized to telomeres in HeLa1.3 cells (Fig. 3C), which contain long $(\sim 25-\mathrm{kb})$ telomeres, facilitating their detection with FISH (Takai et al. 2010).

To assay for the ability of POT $1^{\mathrm{CP}}$ to prevent the activation of ATR signaling at telomeres, we used an shRNA to reduce the level of the endogenous POT1 in HeLa 1.3 cells. As reported previously (Hockemeyer et al. 2005), POT1 
Takai et al.
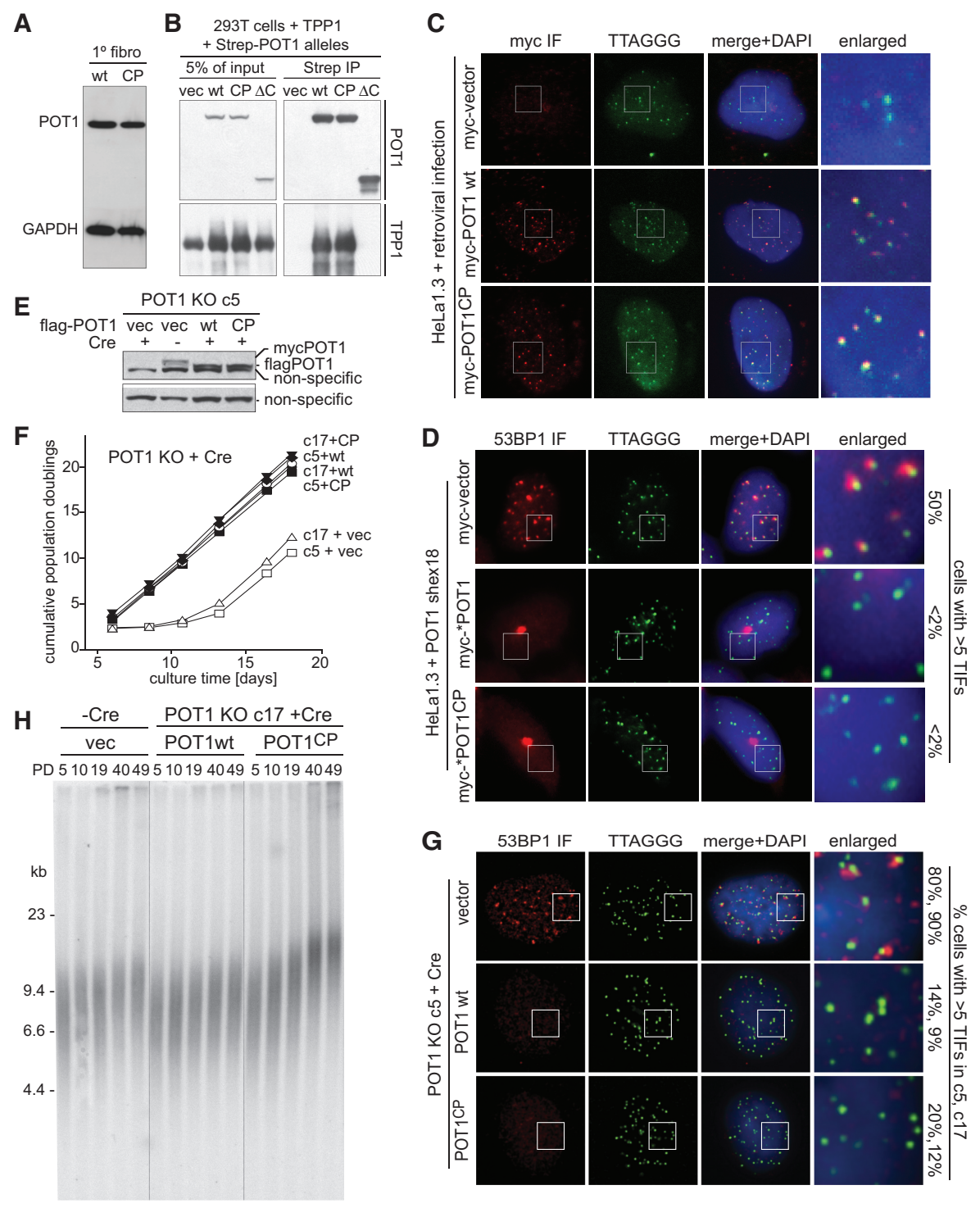

Figure 3. Normal TPP1 binding, localization, repression of ATR signaling, and telomere length control by POT1 ${ }^{\mathrm{CP}}$. $(A) \operatorname{Immunoblot}$ for POT1 and GAPDH (loading control) in normal and POT $1{ }^{\mathrm{CP}}$ primary fibroblasts. (B) Coprecipitation of TPP1 from $293 \mathrm{~T}$ cells cotransfected with wild-type (wt) POT1, POT1 ${ }^{\mathrm{CP}}$, POT1 ${ }^{\Delta \mathrm{C}}$, or empty vector. Strep-tagged wild-type POT1, POT1 ${ }^{\mathrm{CP}}$, or POT1 ${ }^{\Delta \mathrm{C}}$ (amino acids $2-350$; lacking the C-terminal half) were precipitated with Strep-tactin beads and queried for association with TPP1 by immunoblotting. TPP1 was detected with antibody $(\mathrm{Ab})$ 1050, and POT1 was detected with Strep Ab. $(C)$ Localization of wild-type POT1 and POT1 ${ }^{\mathrm{CP}}$ to telomeres in retrovirally transduced HeLa1.3 cells. IF for the myc tag of the expressed POT1 proteins (red) was used together with TTAGGG repeatspecific FISH (green) to detect the localization of POT1 at telomeres. (DAPI) DNA stain. $(D)$ Repression of the DNA damage response induced by POT1 shRNA by both wild-type POT1 and POT1 ${ }^{\mathrm{CP}}$. HeLa1.3 cells were transduced with the indicated retroviruses expressing the shRNA-resistant version (indicated by an asterisk) of POT1 or POT1 ${ }^{\mathrm{CP}}$ and subsequently infected with a POT1 shRNA. The occurrence of 53BP1 foci (red) at telomeres (green) was assayed. Quantification of the cells with five or more TIFs is shown at the right. (E) Immunoblot for POT1 in POT1 knockout (KO) clone c 5 complemented with Flag-tagged wild-type POT1 or POT1 ${ }^{\mathrm{CP}}$. Cells were treated with Cre to delete the floxed myc-tagged POT1. $(F)$ Growth curves of two Cre-treated POT1 knockout clones (c5 and c7) and the same clones complemented with either wild-type POT1 or POT $1^{\mathrm{CP}}$ (as in $\left.E\right)$. (G) Representative images of TIF analysis in clone $\mathrm{c} 5$ on day 5 of Cre transduction. (Red) IF for 53BP1; (green) telomeric FISH; (blue) DNA (DAPI). Quantification of the c5 and c17 cells with five or more TIFs is shown at the right. $(H)$ Telomere length analysis of c17 cells not treated with Cre and Cre-treated c17 cells complemented with the indicated POT1 alleles. A telomere-specific probe to detect TTAGGG repeats was used.

shRNA treatment induced a DNA damage signal at telomeres, as evidenced by the formation of TIFs. The TIFs induced by the POT1 shRNA were repressed by expression of an shRNA-resistant version of wild-type POT1 (Fig. 3D).
Similarly, expression of an shRNA-resistant form of POT $1{ }^{\mathrm{CP}}$ completely repressed the TIF response after depletion of the endogenous POT1 (Fig. 3D). Thus, POT $1^{\mathrm{CP}}$ is largely normal with regard to its expression, interaction 
with TPP1, localization to telomeres, and repression of the acute telomere dysfunction induced by POT1 knockdown in the telomerase-positive HeLa cell line.

$P O T 1^{C P}$ is defective in limiting telomerase-mediated telomere elongation

Most telomeropathies are associated with unusually short telomeres (for review, see Savage and Bertuch 2010), but telomere length measurements in CP patients have not revealed a consistent telomere length phenotype (Anderson et al. 2012; Polvi et al. 2012; Walne et al. 2013). To determine the ability of homozygous POT $1^{\mathrm{CP}}$ to maintain telomere length homeostasis in telomerasepositive cells, we used expression in HT1080 fibrosarcoma cells lacking the endogenous POT1 due to TALEN gene editing (Supplemental Fig. S2A-C). Before TALEN editing of the POT1 locus, the HT1080 cells were infected with a floxed version of myc-tagged human POT1, and a clone (c20.3) was isolated from which floxed POT1 could be efficiently deleted with Cre (Supplemental Fig. S2A). After TALEN editing of clone c20.3, two POT1 knockout clones (c5 and c17) were isolated that lacked the endogenous POT1 due to insertion of a stop cassette in one allele and a TALEN-induced splicing defect in the other (Supplemental Fig. S2B,C). Cre treatment of the cells showed efficient deletion of POT1 (Supplemental Fig. S2C), resulting in loss of POT1 from the telomeres, whereas other shelterin components were not affected (Supplemental Fig. S2D,E). Furthermore, Cre-induced deletion of POT1 resulted in the expected ATR signaling at telomeres and a growth defect (Fig. 3E,F; Supplemental Fig. S2F,G), although cells that had escaped the Cre-mediated deletion of POT1 eventually emerged. The use of POT1 knockout cells to analyze the POT $1{ }^{\mathrm{CP}}$ phenotype has the advantage that it circumvents potential confounding genetic and epigenetic changes associated with the patient cell lines.

The two POT1 knockout clones were infected with Flag-tagged versions of either wild-type POT1 or POT $1{ }^{\mathrm{CP}}$, and the floxed myc-tagged POT1 was deleted with Cre. POT $1^{\mathrm{CP}}$ and wild-type POT1 were expressed at similar levels after deletion of the floxed myc-POT1 (Fig. 3E). The c5 and c17 cultures expressing wild-type POT 1 and $\mathrm{POT}^{\mathrm{CP}}$ proliferated normally after Cre treatment, and, consistent with the data presented above, there was a robust repression of the TIF response by POT ${ }^{\mathrm{CP}}$ (Fig. 3F, $\mathrm{G})$. Thus, in these telomerase-positive cells, POT $1^{\mathrm{CP}}$ does not confer a growth defect.

However, telomere length analysis on cultures maintained for $\sim 50$ PDs showed a gradual increase in telomere length in POT1 knockout cells expressing POT ${ }^{\mathrm{CP}}$ (Fig. $3 \mathrm{H}$; Supplemental Fig. S3A,B) that was abrogated when the cells were treated with the BIBR1532 telomerase inhibitor (see Fig. 4). These results indicate that POT $1^{\mathrm{CP}}$ is deficient in the POT1 function that exerts negative regulation on telomerase. The telomerase-dependent telomere elongation associated with POT $1{ }^{\mathrm{CP}}$ contrasts the developmental and generational telomere shortening observed in most telomeropathies (for review, see Savage and Bertuch 2010).

POT1 ${ }^{C P}$ and $C T C 1^{C P}$ are defective in $3^{\prime}$ overhang
regulation

To determine the possible cause of the telomere dysfunction associated with POT ${ }^{\mathrm{CP}}$ (Fig. 2), we examined the status of the telomeric DNA and the telomeric $3^{\prime}$ overhang. By hybridizing a telomeric CCCTAA repeat probe to telomeric DNA in its native state, the relative abundance of single-stranded TTAGGG repeat DNA can be quantified. The single-stranded TTAGGG repeat signal is normalized to the total TTAGGG repeat signal obtained in the same lane after in situ denaturation of the DNA and rehybridization of the same C-strand probe. These values were then compared between different samples with closely matched telomere lengths to evaluate variations in the relative abundance of the single-stranded TTAGGG repeats.

This approach revealed that the telomerase-negative SV40-LT transformed POT $1^{\mathrm{CP}}$ and $\mathrm{CTC} 1^{\mathrm{CP}}$ patient fibroblasts showed greater single-stranded TTAGGG repeat signals compared with the same cells complemented with the wild-type proteins (Fig. 4A). An increase in the telomeric overhang signal was also observed in the telomerase-positive c5 and c17 POT1 knockout clones complemented with $\mathrm{POT} 1^{\mathrm{CP}}$ as compared with those complemented with wild-type POT1 (Supplemental Fig. S3A-C).

To determine the contribution of telomerase to the increased overhang signals, the complemented POT1 knockout cells were treated with the telomerase inhibitor BIBR1532 (Pascolo et al. 2002). Cre-treated c5 and c17 POT1 knockout cells expressing POT $1^{\mathrm{CP}}$ again showed an increase in the overhang signal as compared with cells expressing wild-type POT1 (Fig. 4B,C). Comparison between the $3^{\prime}$ overhang signal in cells treated with BIBR1532 and those with active telomerase showed that while telomerase made a significant contribution, the increase was unlikely to be solely due to telomerase-mediated elongation of the $3^{\prime}$ overhang (Fig. 4B,C).

The overhang phenotype of POT ${ }^{\mathrm{CP}}$ was further verified in immortalized telomerase-positive clones derived from SV40-LT POT1 ${ }^{\mathrm{CP}}$ fibroblasts infected with an hTERT lentivirus (Fig. 4D,E). Clones from these cells showed a 1.7 -fold to 2.1 -fold increase in the $3^{\prime}$ overhang signal. Treatment with the Escherichia coli $3^{\prime}$ exonuclease Exo1 (exonuclease I) completely removed the singlestranded TTAGGG repeat signal, consistent with it representing the $3^{\prime}$ overhang. No residual $3^{\prime}$ exonuclease-resistant signal was detected. Introduction of wild-type POT1 into the clones diminished the overhang signal by 2.5fold, whereas additional POT $1^{\mathrm{CP}}$ expression did not (Fig. 4D,E).

The effect of POT $1^{\mathrm{CP}}$ on the single-stranded telomeric DNA was also observed in the telomerase-positive HT1080 and HeLa1.3 cells (Supplemental Fig. S3D-H). HT1080 or HeLa1.3 cells treated with a POT1 shRNA to reduce the expression of endogenous POT1 showed a 
Takai et al.
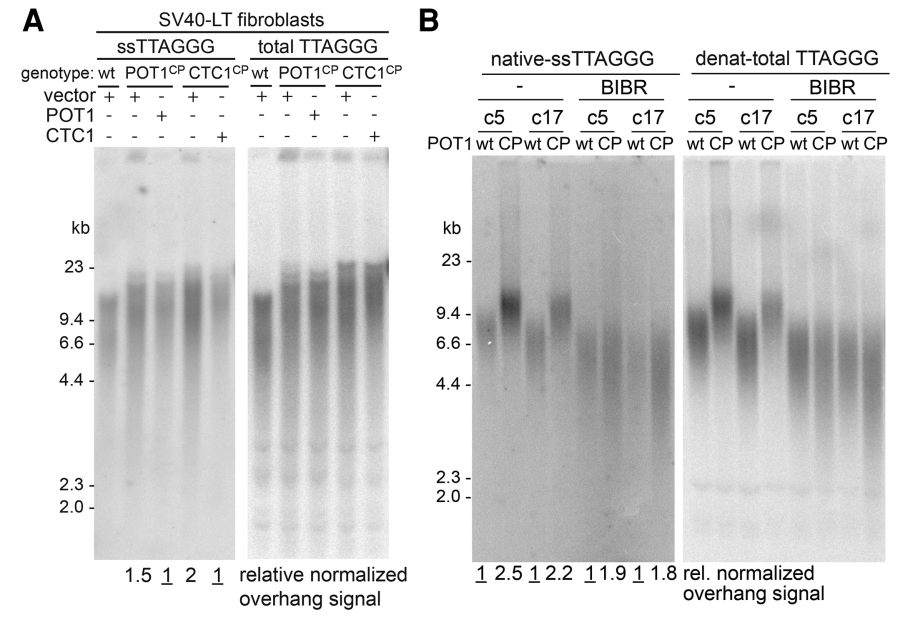

C

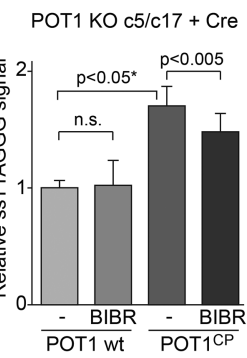

\section{D}
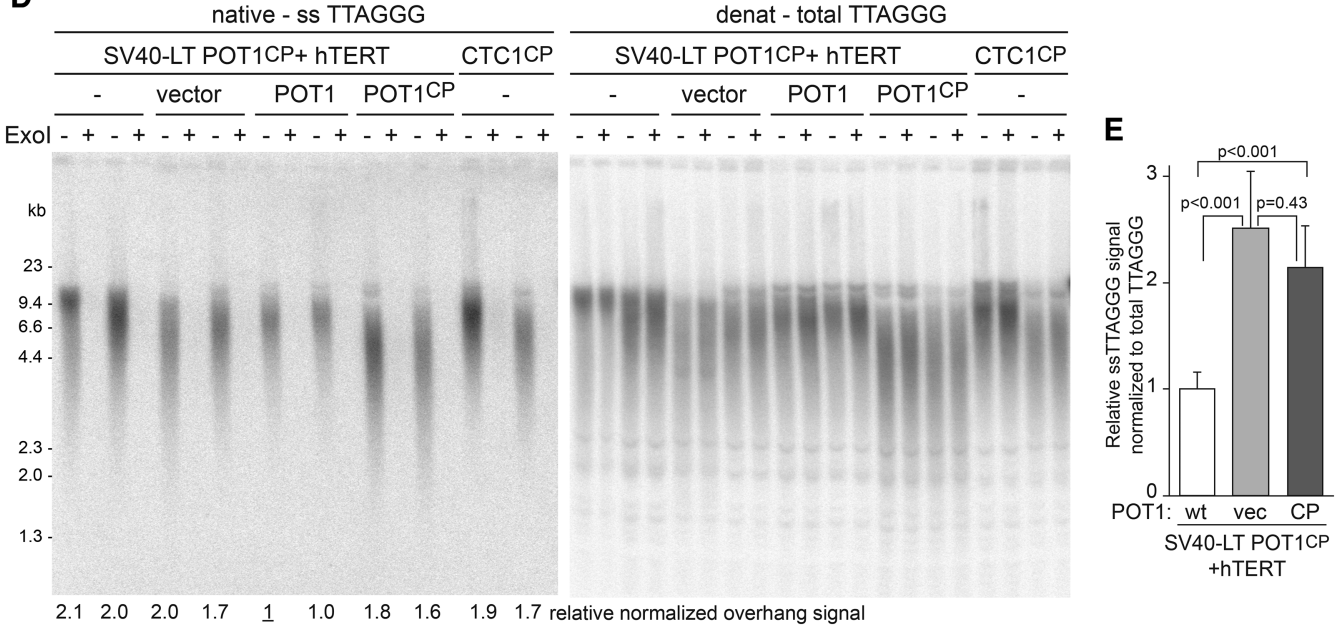

Figure 4. Excess $3^{\prime}$ overhang signal in POT $1^{\mathrm{CP}}$ and $\mathrm{CTC}^{\mathrm{CP}}$ cells. (A) Analysis of single-stranded and total telomeric DNA in SV40-LT transformed normal (wild-type [wt]), POT ${ }^{\mathrm{CP}}$, and $\mathrm{CTC}^{\mathrm{CP}}$ cells transduced to express wild-type POT1 and CTC1 as indicated. The singlestranded (ss) TTAGGG signal (native) was normalized to the total TTAGGG signal (denatured) in the same lane, and these ratios were compared between the lanes with fibroblasts transduced with wild-type POT1 or CTC1 set to 1.0 (underlined). (B) Analysis of singlestranded and total telomeric DNA in Cre-treated ( $21 \mathrm{~d}$ after Cre) POT1 knockout (KO) clones c5 and c17 expressing wild-type POT1 or POT $1^{\mathrm{CP}}$ either not treated or treated with $20 \mu \mathrm{M}$ BIBR1532 for $17 \mathrm{~d}$ to inhibit telomerase. Overhang signals were quantified as in $A$. $(C)$ Quantification of overhang signals performed as shown in $B$ comparing the results of cells with and without BIBR1532 treatment. Values represent the means of eight independent experiments (data on c5 and c17 pooled) with SDs. $P$-values were derived from unpaired $t$ test $\left(^{*}\right)$ and paired $t$-test. $(D)$ Effect of POT $1^{\mathrm{CP}}$ and $\mathrm{CTC} 1^{\mathrm{CP}}$ on the telomeric $3^{\prime}$ overhang in hTERT immortalized fibroblast clones. Two clones were analyzed for each setting. Note that telomere length shows the expected clonal variation. Escherichia coli ExoI treatment $(+)$ confirms the $3^{\prime}$ terminal origin of the single-stranded TTAGGG signal. (E) Quantification of the effect of POT1 ${ }^{\mathrm{CP}}$ on the telomeric $3^{\prime}$ overhang. Data were derived from experiments as in $D$. Values are means and SDs derived from pooling of data on four or more clones per setting. $P$-values were derived from unpaired $t$-test.

1.6-fold greater single-stranded TTAGGG repeat signal when they were complemented with shRNA-resistant POT1 ${ }^{\mathrm{CP}}$ as compared with those complemented with wild-type POT1.

Interestingly, the $\mathrm{CTC}{ }^{\mathrm{CP}}$ clones also showed a substantial increase in the $3^{\prime}$ overhang signal (Fig. 4D), consistent with CST playing a role in the telomere end fill-in step after DNA replication. In contrast to what has been reported previously (Chen et al. 2013), there was no 3' exonuclease-resistant single-stranded TTAGGG signal in cells expressing the CP alleles (Fig. 4D).

\section{$P O T 1^{C P}$ and $C T C 1^{C P}$ cause telomere truncations}

The telomeric DNA fragments from cells expressing POT1 ${ }^{\mathrm{CP}}$ showed a tendency to overpopulate the lower MW range (Fig. 4B; Supplemental Fig. S4). This "smear" below the average telomere length suggested that a subset of the telomeres was truncated. To measure these truncations, we applied the high-resolution telomere length measurement technique STELA (single telomere length analysis), in which PCR is used to amplify the telomeres abutting the pseudoautosomal region of the $\mathrm{X}$ and $\mathrm{Y}$ chromosomes (Baird et al. 2003). 
STELA products showed an abundance of very short telomeres $(<2.3 \mathrm{~kb})$ in primary $\mathrm{CP}$ patient fibroblasts containing either the POT1 $1^{\mathrm{CP}}$ or $\mathrm{CTCl}^{\mathrm{CP}}$ mutation (Fig. 5A). These short products were also observed in SV40-LT transformed POT $1^{\mathrm{CP}}$ fibroblasts (Fig. 5B,C). In contrast, POT $1^{\mathrm{CP}}$ did not affect the nature of the $5^{\prime}$ end (Fig. 5C), which is known to be converted from the canonical ATC-5' sequence to a random position within the $5^{\prime}$-CCCTAA- $3^{\prime}$ repeats when cells are treated with a POT1 shRNA (Hockemeyer et al. 2005; Sfeir et al. 2005).

Extensive telomere truncations were also induced in c5 POT1 knockout cells expressing POT ${ }^{\mathrm{CP}}$ when the cells were treated with the BIBR1532 telomerase inhibitor. POT $1{ }^{\mathrm{CP}}$ expression was associated with a large number of STELA products $<4 \mathrm{~kb}$, including a subset $<2.3 \mathrm{~kb}$ (Fig. 5D).

Even in telomerase-positive patient-derived cells, the presence of POT $1^{\mathrm{CP}}$ or $\mathrm{CTC} 1^{\mathrm{CP}}$ led to a subset of telomeres with STELA products $<4 \mathrm{~kb}$ (Fig. 5E). However, tel- omerase expression appeared to repress the persistence of the severely truncated telomeres, since very few STELA products $<2.3 \mathrm{~kb}$ were detected. This result suggests that the shortened telomeres can be healed by telomerase and explains why telomerase mitigates the growth defect associated with POT $1^{\mathrm{CP}}$.

Such telomere truncations also explain why patientderived CP cells contain 53BP1 foci that do not overlap with telomeric FISH signals (Fig. 2). The severely truncated telomeres are well below the detection limit of our FISH technique so that the DNA damage response at these shortened telomeres will appear as 53BP1 foci that do not colocalize with telomeric signals.

\section{$P O T^{C P}$ induces telomere truncations in metaphase chromosomes}

Because of the induction of telomere truncations by POT $1^{\mathrm{CP}}$, we examined telomeres in metaphase spreads. SV40-LT transformed POT ${ }^{\mathrm{CP}}$ cells showed an increased

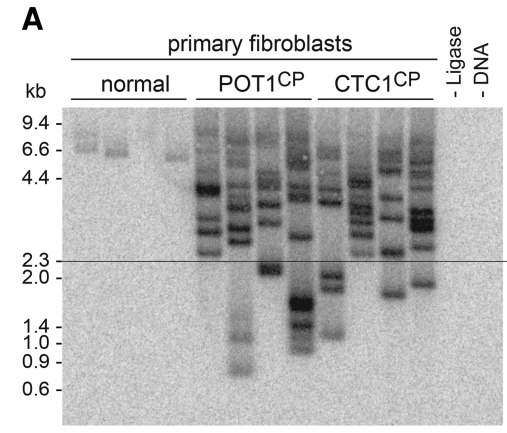

C

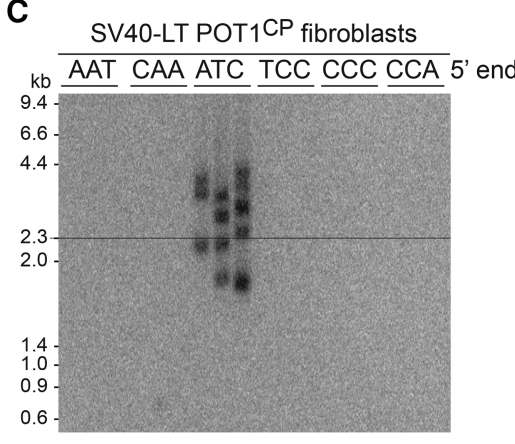

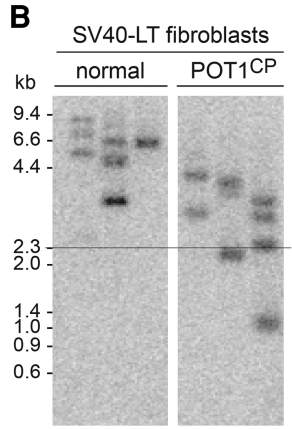

D

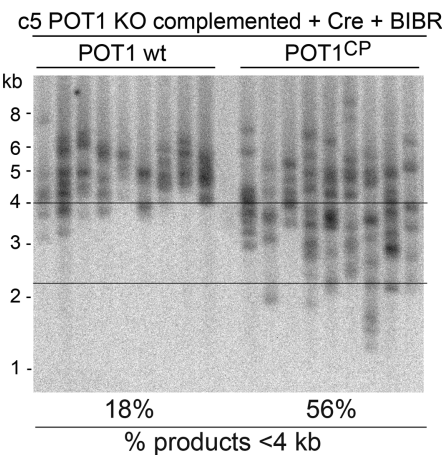

E

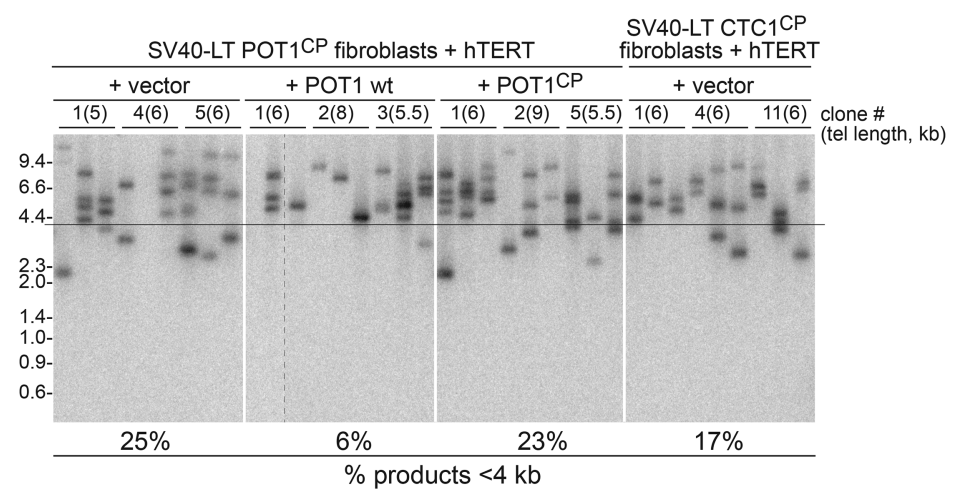

Figure 5. Telomere truncations induced by $\mathrm{POT} 1^{\mathrm{CP}}$ and $\mathrm{CTCl}{ }^{\mathrm{CP}}$ and their healing by telomerase. $(A)$ STELA of truncated telomeres (line at $2.3 \mathrm{~kb}$ ) in primary CP fibroblasts. Normal fibroblasts grown in parallel served as a control. Larger telomeric STELA products are amplified less efficiently, resulting in diminished intensity in the normal fibroblasts. STELA was performed with telorette 3 (ATC- $5^{\prime}$ ends). PCR products from four independent reactions were run in separate lanes. Controls without ligation or genomic DNA are shown. STELA products contain $\sim 0.4$ $\mathrm{kb}$ subtelomeric sequences. $(B)$ Truncated telomeres in $\mathrm{POT} 1^{\mathrm{CP}}$ fibroblasts after transformation with SV40-LT. (C) Canonical ATC-5' ends at telomeres in SV40-LT transformed POT $1^{\mathrm{CP}}$ cells. STELA was performed with six telorettes, each of which ligates to a different $5^{\prime}$ end sequence as indicated. $(D)$ STELA of truncated telomeres in BIBR1532-treated POT1 knockout (KO) c5 cells complemented with wildtype (wt) POT1 or POT $1^{\mathrm{CP}}$. The genomic DNA samples shown in Figure 4B were analyzed. Lines are drawn at $4 \mathrm{~kb}$ and $2.3 \mathrm{~kb}$. STELA products $<4 \mathrm{~kb}$ were quantified. Products $<2.3 \mathrm{~kb}$ were not detected in cells expressing wild-type POT1. (E) Repression of truncated telomeres by hTERT expression in POT $1^{\mathrm{CP}}$ and $\mathrm{CTC} 1^{\mathrm{CP}}$ cells. The indicated SV40-LT CP fibroblasts complemented with POT1, POT $1^{\mathrm{CP}}$, or empty vector were transduced with hTERT, and isolated clones (numbered above the lanes) were analyzed by STELA. Products $<2.3 \mathrm{~kb}$ were absent from hTERT clones. STELA products $<4 \mathrm{~kb}$ were quantified. For each clone used, the mean telomere length, determined by telomeric restriction fragment analysis, is given. 
frequency of chromosome ends demonstrating the (partial) loss of telomeric signals from one of the two sister telomeres (referred to as sister telomere loss) (Fig. 6A,B). The cumulative effect of sister telomere truncations would be expected to lead to chromosome ends lacking all detectable telomeric signals (referred to as signal-free ends), as were observed in POT $1^{\mathrm{CP}}$ cells (Fig. 6A,B). SV40-LT transformed $\mathrm{CTC} 1^{\mathrm{CP}}$ cells also demonstrated an elevated level of signal-free chromosome ends, although this phenotype was less severe than that of POT $1^{\mathrm{CP}}$ fibroblasts (Fig. 6A, B). Sister telomere losses were indistinguishable from background levels, consistent with the milder signal-free end phenotype in $\mathrm{CTC} 1^{\mathrm{CP}}$ cells.

CTC $1^{\mathrm{CP}}$ cells showed the expected increase in fragile telomeres, consistent with the results in CTC1 knockout mouse embryo fibroblasts (MEFs) (Gu et al. 2012) and other data indicating that CST plays a role in the semiconservative replication of telomeres (see above). In contrast, POT ${ }^{\mathrm{CP}}$ cells did not harbor a significant level of fragile telomeres (Fig. 6B), suggesting that telomere replication is not impaired. This result is consistent with the absence of a fragile telomere phenotype in MEFs with telomeres devoid of POT1a and POT1b (Hockemeyer et al. 2006; T de Lange, unpubl.).

To further analyze the effect of POT1 ${ }^{\mathrm{CP}}$ on metaphase telomeres, we used the c5 POT1 knockout cells complemented with $\mathrm{POT} 1^{\mathrm{CP}}$. These cells showed no $(<1 \%)$ fragile telomeres but had a sister telomere loss phenotype after deletion of wild-type POT1 with Cre (Fig. 6C). The sister loss phenotype was quantified by measuring the ratio of the signals of sister telomeres, which is expected to be close to 1. Quantification of the percentage of sister telomeres that deviated in intensity by a factor of $\geq 2.5$ showed a significant increase in sister telomere loss associated with POT1 ${ }^{\mathrm{CP}}$ (Fig. 6D). Thus, the telomere truncations noted from STELA are also observed in metaphase chromosomes.

The sister loss phenotype associated with $\mathrm{POT}{ }^{\mathrm{CP}}$ could be explained by the excessive shortening of the $5^{\prime}$ ended C-rich telomeric repeat strand that was noted on telomeric $3^{\prime}$ overhang analysis. A prediction of this mechanism of telomere truncation is that sister loss in the following metaphase would primarily manifest itself in the telomeres formed through copying of the C-rich repeat
A

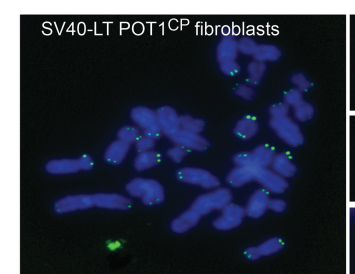

B

\begin{tabular}{lcccc}
\hline cells (\# telomeres scored) & $\begin{array}{c}\text { sister } \\
\text { telomere loss }\end{array}$ & $\begin{array}{c}\text { signal } \\
\text { free ends }\end{array}$ & $\begin{array}{c}\text { fragile } \\
\text { telomeres }\end{array}$ \\
\hline SV40-LT normal $(3602)$ & $1.3 \%$ & $1.0 \%$ & $1.9 \%$ \\
SV40-LT POT1CP ${ }^{(5542)}$ & $3.4 \%^{*}$ & $4.1 \%^{* *}$ & $2.1 \%$ \\
SV40-LT CTC1CP ${ }^{(4984)}$ & $2.4 \%$ & $2.5 \%^{* *}$ & $3.3 \%$ \\
\hline
\end{tabular}

C

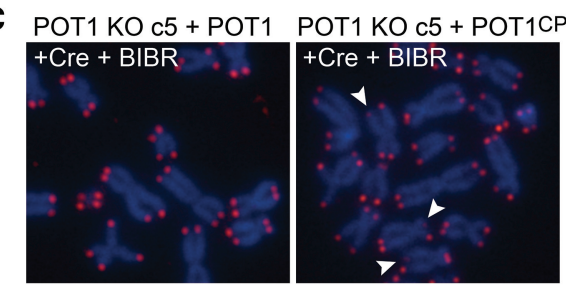

E

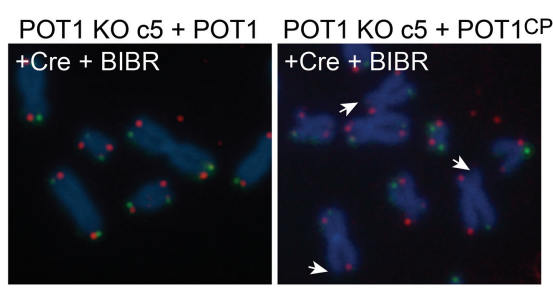

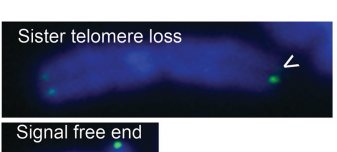

D POT1 KO c5 +Cre +BIBR

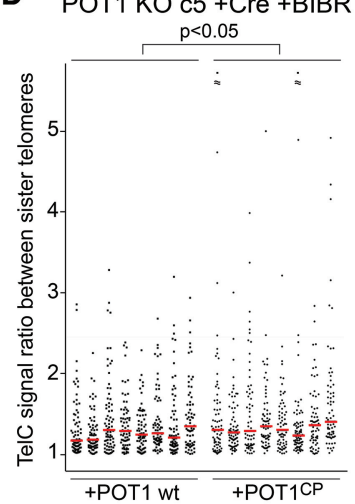

$\mathbf{F}$

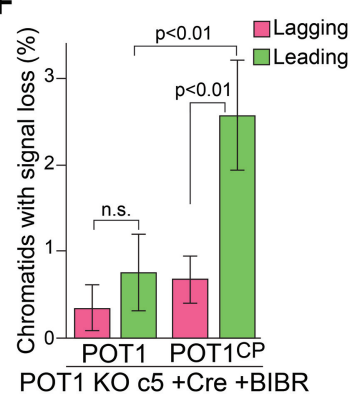

Figure 6. $\mathrm{POT} 1^{\mathrm{CP}}$ induces truncations of leading end telomeres. (A) Metaphase chromosomes from SV40-LT transformed POT $1{ }^{\mathrm{CP}}$ fibroblasts. Telomeres were visualized by FISH (green), and DNA was stained with DAPI (blue). Enlarged images show examples of the telomere aberrations that were scored. Arrowheads indicate defective telomeres. (B) Quantification of telomere losses and fragile telomeres in the indicated SV40-LT transformed fibroblasts. $\left({ }^{*}\right) P<0.05$; $\left(^{* *}\right) P$ $<0.01$. $P$-values (based on unpaired $t$-test) in comparison with normal SV40-LT cells. (C) FISH for telomeric DNA in metaphase spreads of Cre-treated POT1 knockout (KO) clone c5 complemented with wild-type POT1 or POT ${ }^{\mathrm{CP}}$. Representative images of c 5 cells treated with BIBR1532 for $4 \mathrm{~d}$ (day 8 after Cre transduction) are shown. Telomere lengths were $6.5 \mathrm{~kb}$ in both cases. Arrowheads indicate chromosome ends with the sister telomere signal ratio 2.5 times or more. $(D)$ Quantification of the sister telomere intensity ratios in individual metaphase spreads as in $C$. Each column represents one metaphase. The number of telomeres showing a sister telomere intensity ratio 2.5 or more was significantly increased in POT1 knockout c5 cells complemented with POT ${ }^{C P}$. $P$-value was derived from unpaired $t$-test. The dotted line shows the sister telomere signal ratio at 2.5. Median signal ratios are shown with red lines. (E) Chromosome orientation FISH (CO-FISH) to detect the telomeres replicated by leading (green) and lagging (red) DNA synthesis on the cell lines as in $C$. Arrows indicate chromosome ends with diminished leading strand telomere signals. Representative images from POT1 knockout c5 cells treated with BIBR 1532 for $11 \mathrm{~d}$ (day 15 after Cre transduction) are shown. $(F)$ Quantification of loss of the leading and lagging end telomeres detected as in $E$. Analysis was performed in Cre-treated (15 $\mathrm{d}$ after Cre) POT1 knockout clones c5 and c17 expressing wild-type POT1 or POT1 ${ }^{\mathrm{CP}}$ treated with BIBR 1532 for $11 \mathrm{~d}$ to inhibit telomerase. Values are means and SDs from three independent experiments. In total, 5776 and 6082 chromatid ends from POT1 knockout cells complemented with wild-type POT1 or POT1 ${ }^{\mathrm{CP}}$ were scored (data on c5 and c17 pooled). $P$-values were derived from unpaired $t$-test. (n.s.) Not significant. 
strand by leading strand DNA synthesis. Indeed, chromosome orientation FISH (CO-FISH) to measure truncations of telomeres formed by leading and lagging strand DNA synthesis revealed that the POT $1^{\mathrm{CP}}$-induced truncations primarily affected the leading end telomeres (Fig. 6E,F).

Collectively, our data indicate that POT $1^{\mathrm{CP}}$ and $\mathrm{CTC1}^{\mathrm{CP}}$ cells experience stochastic losses of telomeric DNA, explaining the 53BP1 foci in the POT1 ${ }^{\mathrm{CP}}$ and $\mathrm{CTC1}{ }^{\mathrm{CP}}$ cells and their proliferative arrest. These telomere truncations can be healed by telomerase, allowing telomerase-expressing cells to overcome the consequences of the CP phenotype.

\section{Discussion}

We propose that the homozyogous S322L change in the shelterin component POT1 can cause CP. Although only one CP family with mutations in POT1 was identified, our mapping and sequencing data, together with the fact that wild-type POT1 can repress the proliferation defect and the telomere dysfunction phenotypes observed in patient fibroblasts, strongly argue that the POT1 variant is the cause of the disease. The involvement of POT1 further supports the idea that CP is a telomere disease. Whereas the CST complex is implicated in the replication of genome-wide loci (Stewart et al. 2012), POT1 is a specific telomeric DNA-binding protein whose known functions are limited to telomeres. Since the data indicate that $\mathrm{POT} 1^{\mathrm{CP}}$ represents a recessive separation-of-function rather than a null allele, very few mutations of this kind might be expected in CP families.

We observed expression levels of POT ${ }^{\mathrm{CP}}$ protein in patient cells comparable with wild type as well as normal telomere localization and interaction of mutant POT1 with TPP1. POT $1^{\mathrm{CP}}$ was also proficient in repressing ATR kinase signaling at telomeres and capable of dictating the exact sequence at the $5^{\prime}$ end of the chromosome. POT $1^{\mathrm{CP}}$ was defective in controlling telomerase, leading to overelongated telomeres. This phenotype is unlikely to be pathogenic in $\mathrm{CP}$, since most $\mathrm{CP}$ patients do not show unusually long telomeres.

The likely cause of CP is revealed by the observation that $\mathrm{POT} 1^{\mathrm{CP}}$ failed to protect telomeres from sudden deletions, resulting in excessively short telomeres that have likely lost the ability to protect chromosome ends. In particular, mutant patient cells contained telomeric STELA products $<2.3 \mathrm{~kb}$, which have been correlated with telomere dysfunction and fusion (Lin et al. 2014). The finding that telomerase can immortalize the POT $1^{\mathrm{CP}}$ cells and diminishes the presence of the extremely short telomeres argues in favor of the shortened telomeres causing the observed proliferation defect.

\section{Common telomere phenotypes of POT1 ${ }^{C P}$ and $C T C 1^{C P}$ as the cause of $C P$}

It is not known what type of telomere dysfunction is the proximal cause of CP. We consider it likely that CP is the result of a telomere dysfunction phenotype that is shared between POT $1^{\mathrm{CP}}$ and the CTC1-associated form of the disease (Fig. 7A). One feature common to both molecular forms of $\mathrm{CP}$ is a defect in telomere end processing leading to extended $3^{\prime}$ overhangs. These extended overhangs are thought to arise from Exol-dependent resection of the $5^{\prime}$ end of telomeres after DNA replication (Fig. 7B; Wu et al. 2012). We note that this aspect of telomere biology has not yet been addressed in human cells, and it is not

A

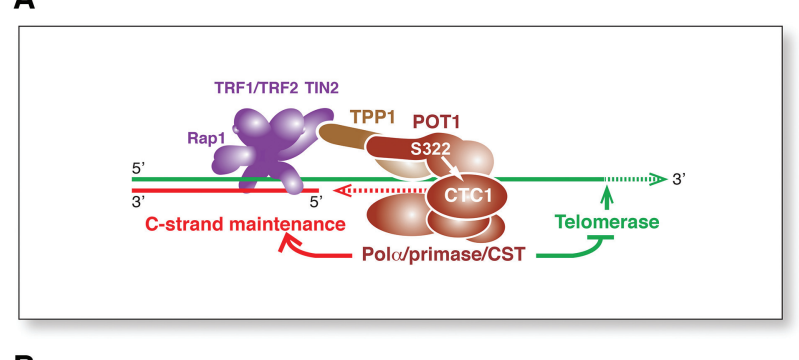

B

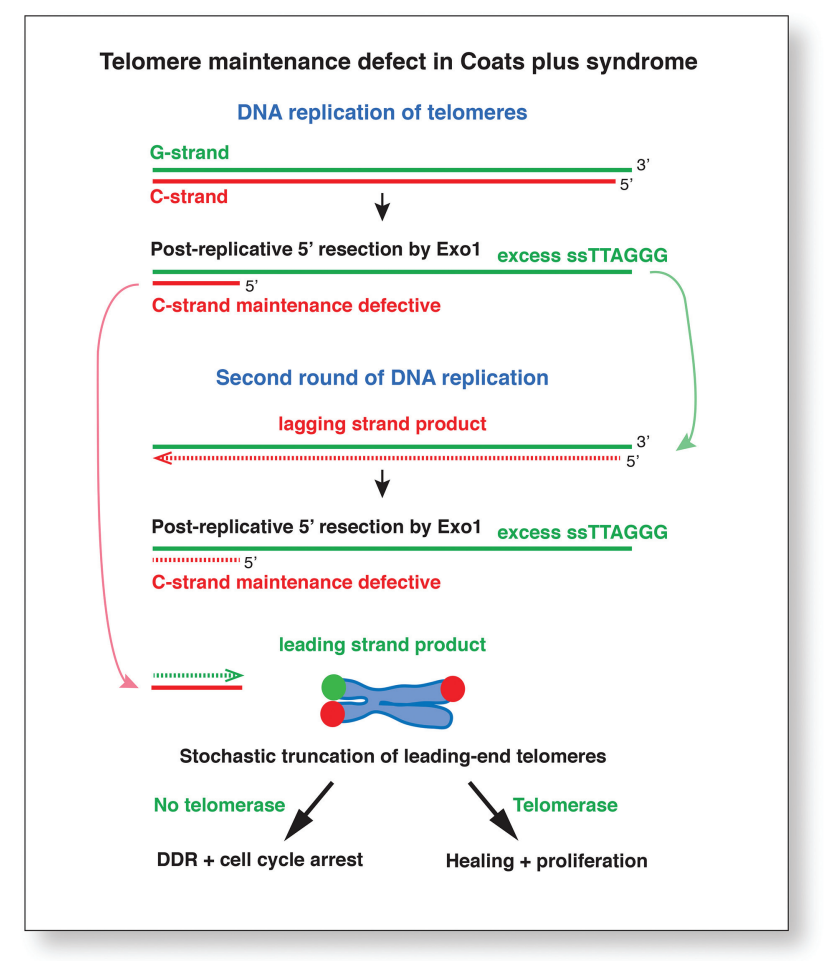

Figure 7. Proposed consequences of POT1 and CTC1 mutations in CP. (A) Model of the mechanism by which POT1 and CTC1 mutations lead to CP. According to the depicted speculative model, both the POT1 S322L substitution and the CP CTC1 mutations interfere with the function of CTC1 in promoting the pola/primase-dependent fill-in of replicated telomere ends. Without this fill-in, the long $3^{\prime}$ overhangs generated by the Exol $5^{\prime}$ nuclease will persist. In addition, both types of CP mutations abrogate or diminish the negative regulation of telomerase, leading to extended telomeres. $(B)$ Schematic depicting how diminished telomere C-strand fill-in can lead to telomere truncations of the leading end telomeres and cell cycle arrest. In cells with telomerase, the CP phenotype can be suppressed through healing of the truncated telomeres. 
excluded that the Apollo nuclease plays a role in nucleolytic attack on the $5^{\prime}$ telomeres (Lenain et al. 2006; Wu et al. 2010, 2012). In mouse cells, the resulting long overhangs are normally filled in by CST and its associated pola/primase (Fig. 7). The second phenotype shared by POT $1^{\mathrm{CP}}$ and $\mathrm{CTC} 1^{\mathrm{CP}}$ is the presence of severely truncated telomeres that can be detected by STELA and were revealed as signal-free chromosome ends in metaphase.

We propose that the two cellular phenotypes held in common by POT $1^{\mathrm{CP}}$ and $\mathrm{CTC} 1^{\mathrm{CP}}$ are linked such that the truncated telomeres result from duplication of shortened C-rich telomeric strands at telomeres where CSTmediated fill-in has failed (Fig. 7B). We further propose that $\mathrm{CP}$ arises when telomere truncations induce proliferative arrest. The loss of protection at a few telomeres and the concomitant ATM/ATR DNA damage signaling would be expected to induce senescence or apoptosis despite the adequate telomere reserve at most chromosome ends. Only the expression of telomerase, as modeled here with POT $1^{\mathrm{CP}}$ and $\mathrm{CTC} 1^{\mathrm{CP}}$ cells, can alleviate the effect of ongoing telomere truncations in mutant cells. Therefore, this type of telomere dysfunction is predicted to induce pathology in tissues where telomerase is repressed during development, whereas cellular compartments that retain telomerase expression (e.g., bone marrow stem cells and intestinal stem cells) may be less affected. Notably, such telomere truncations are predicted to give rise to $\mathrm{CP}$ even when the average telomeres are long, explaining the existence of CP patients with no obvious average telomere length defect (e.g., Polvi et al. 2012; this study).

The most severe telomere truncations observed in cells expressing POT $1^{\mathrm{CP}}$ or $\mathrm{CTC} 1^{\mathrm{CP}}$ removed many kilobases of telomeric DNA. However, the average increase in the telomeric overhang signal is only twofold, which, assuming that the telomeric overhangs are in the 35- to 600-nucleotide range (Sfeir et al. 2005), appears insufficient to explain the observed telomere truncations. However, as Exol is processive in vitro (Nimonkar et al. 2011; Myler et al. 2016), there may be a wide range in overhang lengths in cells lacking normal CST function. Indeed, in fungi and plants, impaired CST function results in extensive degradation of the 5' end of telomeres (Garvik et al. 1995; Martin et al. 2007; Song et al. 2008). Similarly, long overhangs and severely truncated telomeres are induced by deletion of mouse CTC1, although the sudden telomere losses in CTC1-null cells were interpreted as products of replication stress (Gu et al. 2012).

A simple explanation for the common phenotypes of POT $1^{\mathrm{CP}}$ and $\mathrm{CTC} 1^{\mathrm{CP}}$ would be that POT1 recruits and/ or positions CST at telomeres in a manner that is altered by POT $1^{\mathrm{CP}}$ (Fig. 7A). Indeed, human POT1, like mouse POT1b, has been shown to interact with CST /Chen et al. 2012; Diotti et al. 2014), and the S322L mutation in human POT1 is very close to the CST interaction site in mouse POT1b (Wu et al. 2012). It will therefore be of interest to execute a detailed analysis of the POT1-CST interaction using wild-type and CP mutant proteins. Unfortunately, our attempts to monitor changes in the POT1-CST interactions have been thwarted by their weak interaction.
Interestingly, mice do not survive without POT1b when telomerase is also absent $\left(\mathrm{mTR}^{-l-}\right)$ (Hockemeyer et al. 2008). This result is not readily explained by the accelerated telomere shortening (Hockemeyer et al. 2008). Possibly, the occurrence of telomere truncations due to insufficient CST-mediated fill-in of the telomere ends may be the cause of POT1b/mTR double knockout lethality, similar to what is proposed for CP.

\section{The role of telomere replication stress in $C P$}

It was previously suggested that $\mathrm{CP}$ is caused primarily by a telomere replication defect (Chen et al. 2013). This view arose from the observation that a battery of $\mathrm{CTC}^{\mathrm{CP}}$ proteins, when tested by overexpression in HT1080 cells, consistently resulted in an excess of ExoI-resistant single-stranded TTAGGG DNA. These single-stranded TTAGGG repeats are assumed to represent unrepaired single-stranded gaps resulting from telomere replication defects. The proposal that CP mutant CTC1 induces telomere replication stress is consistent with the occurrence of fragile telomeres in the CTC1 cells noted here (but not in two other CP patient fibroblasts) (Polvi et al. 2012), the induction of fragile telomeres by depletion of components of human CST (Stewart et al. 2012; Kasbek et al. 2013), and the fragile telomere phenotype upon deletion of mouse CTC1 (Gu et al. 2012). However, ExoI-resistant single-stranded TTAGGG repeat DNA was not observed in $\mathrm{CTC} 1^{\mathrm{CP}}$ cells (this study) or CST knockdown cells despite the presence of fragile telomeres (Surovtseva et al. 2009; Kasbek et al. 2013). Furthermore, in other situations where telomere replication is severely affected (e.g., deletion of TRF1 from mouse cells), no increase in the single-stranded TTAGGG repeat signal was observed (Sfeir et al. 2009; Martinez et al. 2010), and mouse cells with a temperature-sensitive pola show no increase in telomere-internal single-stranded TTAGGG repeats at the nonpermissive temperature, while their $3^{\prime}$ overhang signal doubles (Nakamura et al. 2005). We therefore propose that the increase in single-stranded TTAGGG repeats observed upon diminished CST function is primarily caused by a failure of pola/primase to fill in telomere ends. This fill-in phenotype, but not the fragile telomeres associated with replication stress, occurs in both $\mathrm{CTC} 1^{\mathrm{CP}}$ and POT $1^{\mathrm{CP}}$ cells and is therefore a prime candidate for the molecular basis of CP.

\section{CST and POT1 as negative regulators of telomerase: working together?}

POT1 has long been known to act as a negative regulator of telomerase, but its mechanism of action has not been established. Extensive telomere elongation occurs upon overexpression of the POT $1 \Delta \mathrm{OB}$ mutant or a C-terminal fragment of POT1, both of which are dominant-negative mutants that lack DNA-binding activity but retain their telomeric localization through TPP1 (Loayza and de Lange 2003; Liu et al. 2004). Similarly, telomere elongation is observed upon POT1 knockdown with shRNA in telomerase-positive cells (Ye et al. 2004). More recently, 
CST has emerged as a second negative regulator of telomerase-mediated telomere extension in human cells /Chen et al. 2012). Diminished CST expression or overexpression of a dominant-negative allele of CTC1 results in rapid elongation in cells that normally maintain telomeres at a short length setting (Chen et al. 2012), although this effect may be variable among telomerase-positive cell lines (Kasbek et al. 2013). Furthermore, inactivation of a temperature-sensitive allele of pola in mouse cells results in telomere elongation, as does inhibition of this polymerase with aphidicolin in human cells (Nakamura et al. 2005; Sfeir et al. 2009). Our data on the similarity of the overhang and telomere truncation phenotypes seen with the POT1 and CTC1 CP-associated mutant alleles now suggest that these two regulatory pathways of telomerase may be related such that POT1 regulates telomerase through the action of CST (Fig. 7A). Consistent with this view, both the POT $1^{\mathrm{CP}}$ and the $\mathrm{CTC} 1^{\mathrm{CP}}$ cells show a deficiency in telomerase inhibition, as the overhangs are more elongated than in cells with wild-type POT1, and the telomeres show extensive elongation. It will be of interest to further explore the possibility that POT1 regulates telomerase in part through recruitment and/or positioning of CST at telomeres.

\section{Materials and methods \\ Genotyping analysis and autozygosity mapping}

A genome-wide SNP microarray using the Affymetrix Human SNP array 6.0 (Affymetrix) was performed in affected siblings according to the manufacturer's instructions. Regions of autozygosity were identified using AutoSNPa software with build GRCh37/hg19 (http://dna.leeds.ac.uk/autosnpa; Carr et al. 2006).

\section{PCR and Sanger sequencing}

Genomic DNA was extracted from whole blood of affected individuals and parents using standard techniques. PCR was performed using Abgene AB575 master mix, and sequencing was carried out using BigDye terminator cycle sequencing system version 3.1. All primers were designed using Primer3 software (Untergasser et al. 2012). For primer sequences, see Supplemental Table S1.

\section{Senescence-associated $\beta$-galactosidase staining}

Primary fibroblasts were grown through an equivalent number of passages (passaged at a ratio of 1:2 each time). Cells were fixed and stained using the senescence $\beta$-galactosidase staining kit (Cell Signaling Technology, \#9860) in accordance with the manufacturer's instructions.

\section{Cell culture}

Primary human fibroblasts were maintained in DMEM (Corning) with $15 \%$ fetal bovine serum (Gibco), 2 mM L-glutamine, $100 \mathrm{U} /$ $\mathrm{mL}$ penicillin, $0.1 \mathrm{mg} / \mathrm{mL}$ streptomycin, $0.1 \mathrm{mM}$ nonessential amino acids (NEAA), $1 \mathrm{mM}$ sodium pyruvate, and $50 \mathrm{mM} \beta$-mercaptoethanol. Prior to and during the SV40-LT transformation, fibroblasts were grown at $7 \%(\mathrm{v} / \mathrm{v}) \mathrm{CO}_{2}$ and $2 \%(\mathrm{v} / \mathrm{v}) \mathrm{O}_{2}$. Cells were transformed with lentiviral SV40-LT and then transduced with POT1 Ex18 shRNA-resistant N-terminal myc-tagged POT1
(pLPC-mycPOT1), POT1 S322L (pLPC-mycPOT1 ${ }^{\mathrm{CP}}$ ), or control retrovirus (pLPC-myc). These cell lines and SV40-LT transformed CTC ${ }^{\mathrm{CP}}$ cells were subsequently transduced with lentiviral hTERT (pLVX myc-hTERT-IRES-Hyg; a gift from T. Davoli). After the hTERT infection, individual colonies were picked and expanded. hTERT-expressing fibroblasts and other human lines were maintained under normoxic conditions with $5 \%(\mathrm{v} / \mathrm{v}) \mathrm{CO}_{2}$ in DMEM with $10 \%$ bovine calf serum (Hyclone), L-glutamine, penicillin, streptomycin, and NEAA as above. POT1 shRNAs used were pSuperior POT1 Ex18 (Hockemeyer et al. 2005) and pLKO.1 POT1 635 (target site: 5'-GGAGCATCATTTCTTC TAA-3') (Sigma). Retroviral and lentiviral gene delivery was performed as described (Wu et al. 2012). For Cre recombinase transduction, cells were infected twice at 12-h intervals with pMMP Hit\&Run Cre. The ATR inhibitor ETP-46464 (Toledo et al. 2011) was used at $1 \mu \mathrm{M}$.

\section{TALEN-mediated human POT1 gene targeting}

The heterodimeric TALEN pair for human POT1 gene targeting was constructed using the following RVD sequences. left, 5'-NINI-NI-NI-NG-NI-NG-NG-NN-NI-NI-NI-NN-NG-HD-NI-NN$3^{\prime}$; and right, $5^{\prime}$-NN-NI-NN-HD-NI-NI-NG-NI-NI-NG-HD-NGNN-NN-NI-3'. TALENs were constructed using the Flash assembly system (Reyon et al. 2012). The PGK Neomycin cassette from the PL451 vector (National Cancer Institute) was ligated into pSL301 (Invitrogen) using NheI and BamHI sites. The stop cassette was digested out of Lox-Stop-Lox TOPO (Addgene) (Jackson et al. 2001) with BamHI and EcoRI and cloned into the relevant sites of the neomycin donor constructs. The $5^{\prime}$ and $3^{\prime}$ homology arms were PCR-amplified with restriction site overhangs from genomic HT1080 DNA. Primers for PCR of the $5^{\prime}$ arm were as follows: 5'-CTACCACCAGTGTTTGAAGTTATCG-3' and 5'-AA TATTTTACCTGACTTTCAATATTTTAAAGC-3'. Primers for PCR of the $3^{\prime}$ arm were $5^{\prime}$-CTCTGTATTGTTCACTGAAAC TAGTTAGCAC- $3^{\prime}$ and $5^{\prime}$-CCAGAAGTGCATTGAACAAAAAA GCTC-3'. The resulting 647-base-pair (bp) 5' homology arm ended $14 \mathrm{bp}$ from the intron 6/exon 7 junction and had XhoI and NheI sites on the $5^{\prime}$ and $3^{\prime}$ ends, respectively. The resulting 649-bp $3^{\prime}$ homology arm started $43 \mathrm{bp}$ from the exon $3 /$ intron 3 junction and had EcoRI restriction $5^{\prime}$ and a blunt $3^{\prime}$ end. The homology arms were cloned into the relevant restriction sites in pSL301 containing the PGK Neomycin. Gene targeting was conducted as previously described (Kabir et al. 2014). Genotyping PCR used the following primers: POT1 primers (F1: 5'-GTGTA CTTCAGAACCATGTATAGCACACC-3', R1: 5'-GGGCTTCA TAGTTTCCACTAAAGAGCAGGC-3') and PGK internal primer (R2: 5'-CATCTGCACGAGACTAGTGAGACGTGCTAC-3').

\section{Telomeric chromatin immunoprecipitation (ChIP)}

Telomeric ChIP was conducted as previously described (Loayza and de Lange 2003). The following antibodies (Abs) or crude sera were used: myc (Cell Signaling, 9B11), POT1 (Abcam, ab124784), TRF1 (rabbit polyclonal, 371), TRF2 (rabbit polyclonal, 647), Rap1 (rabbit polyclonal, 765), TIN2 (rabbit polyclonal, 864), and TPP1 (rabbit polyclonal, 1151).

\section{IF-FISH and immunoblotting}

For IF, cells grown on coverslips were incubated for 1 min with Triton X-100 extraction buffer $(0.1 \%$ Triton X-100, $20 \mathrm{mM}$ HEPES-KOH at $\mathrm{pH} 7.9,50 \mathrm{mM} \mathrm{NaCl}, 3 \mathrm{mM} \mathrm{MgCl}_{2}, 300 \mathrm{mM}$ sucrose) on ice, fixed with $3 \%$ paraformaldehyde (PFA)/ $2 \%$ sucrose in PBS for $10 \mathrm{~min}$, and processed for IF-FISH as described 
(Wu et al. 2012). Abs for IF were as follows: myc (Cell Signaling, 9B11), 53BP1 (Novus, 100-305), and $\gamma$-H2AX (Millipore, JBW301). Protein coimmunoprecipitation assay was performed as follows: Full-length wild-type POT1, POT $1^{\mathrm{CP}}$, and POT1 lacking the $\mathrm{C}$ terminus $\left(\mathrm{POT}^{\Delta \mathrm{C}}\right.$; amino acids 2-350) were cloned into pQE Strep2 (Qiagen). N-terminally Strep-tagged POT1 proteins were coexpressed with hTPP1 (pLPC-hTPP1) in 293T cells. $293 \mathrm{~T}$ cells $\left(1 \times 10^{6}\right.$ per $10-\mathrm{cm}$ dish $)$ were plated $24 \mathrm{~h}$ prior to calcium phosphate transfection. Cells were scraped into cold PBS at 36-48 h after transfection, collected by centrifugation, and lysed in cold lysis buffer $(50 \mathrm{mM}$ Tris- $\mathrm{HCl}$ at $\mathrm{pH} 7.5,150 \mathrm{mM} \mathrm{NaCl}, 0.5$ $\mathrm{mM} \mathrm{MgCl} 2,0.1 \%$ SDS, $1 \%$ Triton X-100, 1 mM DTT, Complete protease inhibitor mix [EDTA-free; Sigma]). After $5 \mathrm{~min}$ on ice, $\mathrm{NaCl}$ was added to $400 \mathrm{mM} ; 5$ min later, ice-cold $\mathrm{H}_{2} \mathrm{O}$ was added to lower the $\mathrm{NaCl}$ concentration to $200 \mathrm{mM}$, and the lysate was immediately centrifuged at $15,000 \mathrm{rpm}$ for $10 \mathrm{~min}$ at $4^{\circ} \mathrm{C}$. Supernatants were collected, supplemented with $100 \mathrm{U} / \mathrm{mL}$ benzonase nuclease (Sigma), and used for coprecipitation by adding $70 \mu \mathrm{L}$ of Strep-Tactin Superflow beads (Qiagen) per sample. Following $2 \mathrm{~h}$ of incubation at $4^{\circ} \mathrm{C}$, beads were washed once with lysis buffer containing $400 \mathrm{mM} \mathrm{NaCl}$ and twice in lysis buffer with 150 $\mathrm{mM} \mathrm{NaCl}$. Proteins were eluted with Laemmli loading buffer and analyzed by immunoblotting using Strep tag (Qiagen, 34850) for POT1 and Ab 1150 (Hockemeyer et al. 2007) for TPP1. In other immunoblots, POT1 was detected with $\mathrm{Ab}$ 124784 (Abcam), and GAPDH was detected with Ab 5174 (Cell Signaling).

\section{Metaphase spreads}

Telomeric FISH and CO-FISH on metaphase spreads were performed as described previously (Celli and de Lange 2005).

\section{STELA}

STELA was performed as described previously (Baird et al. 2003; Sfeir et al. 2005). Briefly, $2 \mu \mathrm{g}$ of genomic DNA was digested with EcoRI (New England Biolabs) overnight at $37^{\circ} \mathrm{C}$. Ten nanograms of digested DNA was ligated to telorettes in $10 \mu \mathrm{L}$ of ligation buffer ( 5 U of T4 DNA ligase [New England Biolabs], $1 \times$ ligase buffer [New England Biolabs], $0.18 \mathrm{nM}$ individual telorettes) overnight at $35^{\circ} \mathrm{C}$. Ligated DNA ( $250 \mathrm{pg}$ ) was amplified by PCR in 25 $\mu \mathrm{L}$ of PCR mix $(0.2 \mu \mathrm{M}$ XpYpE2 primer, $0.2 \mu \mathrm{M}$ teltail primer, $1 \times$ Fail Safe PCR buffer H, 2 U of Fail Safe enzyme mix [Epicentre] with 27 cycles $\left[15 \mathrm{sec}\right.$ at $95^{\circ} \mathrm{C}, 20 \mathrm{sec}$ at $58^{\circ} \mathrm{C}$, and 9 min at $68^{\circ}$ C]). PCR products were resolved on a $0.7 \%$ agarose/TAE gel, blotted onto Hybond (GE Healthcare), UV cross-linked in a Stratalinker, prehybridized with Church mix $(0.5 \mathrm{M}$ sodium phosphate buffer at $\mathrm{pH} 7.2,1 \mathrm{mM}$ EDTA, $0.7 \%$ SDS, $0.1 \%$ BSA), and hybridized overnight at $55^{\circ} \mathrm{C}$ with Klenow $\left[\alpha-{ }^{32} \mathrm{P}\right]$ dCTP-labeled XpYp probe in Church mix. Membranes were rinsed three times for $15 \mathrm{~min}$ each in Church wash $140 \mathrm{mM}$ sodium phosphate buffer at $\mathrm{pH} 7.2,1 \mathrm{mM}$ EDTA, 1\% [w/v] SDS) at $55^{\circ} \mathrm{C}$ and exposed to PhosphorImager screens.

\section{Telomeric overhang analysis}

In-gel telomeric overhang assay was performed on DNA embedded in plugs as described (Hemann and Greider 1999) with minor modifications as described previously (Wu et al. 2012) using $60 \mathrm{U}$ of MboI and $60 \mathrm{U}$ of AluI for digestion. For E. coli 3' ExoI (New England Biolabs) treatment, plugs were equilibrated in Exo1 buffer (67 mM glycine- $\mathrm{NaOH}$ at $\mathrm{pH} 9.5,6.7 \mathrm{mM} \mathrm{MgCl}_{2}, 10 \mathrm{mM} \beta$-mercaptoethanol) and treated twice with $100 \mathrm{U}$ of ExoI in $1 \mathrm{~mL}$ of ExoI buffer for $10 \mathrm{~h}$ each at $37^{\circ} \mathrm{C}$. The plugs were washed extensively in TE before restriction endonuclease digestion.

\section{Acknowledgments}

We are very grateful to the affected family. We thank the members of the de Lange laboratory for useful comments on this study. Dr. Isabelle Schmutz is thanked for help with determining sister telomere ratios. Y.J.C. acknowledges the Manchester National Institute for Health Research (NIHR) Biomedical Research Centre. This work has received support from the Great Ormond Street Hospital Children's Charity and the Newlife Foundation as well as grants to T.d.L. from the National Cancer Institute (1R01CA181090) and the National Institute of Aging (AG16642). H.T. performed the experiments shown in Figures 2-6 and Supplemental Figures S3 and S4 using primary fibroblasts provided by E.J. and POT1 knockout clones generated by S.K. E.J. cultured primary fibroblasts and generated the data in Supplemental Figure S1. S.K. generated the data in Supplemental Figure S2. R.B.-H., D.A.C., and N.N.-T. ascertained the affected children described here. E.J. and Y. J.C. executed the genetic analysis in Figure 1. T.d.L. wrote the paper with the help of the other authors.

\section{References}

Anderson BH, Kasher PR, Mayer J, Szynkiewicz M, Jenkinson EM, Bhaskar SS, Urquhart JE, Daly SB, Dickerson JE, O'Sullivan J, et al. 2012. Mutations in CTC1, encoding conserved telomere maintenance component 1 , cause Coats plus. Nat Genet 44: 338-342.

Baird DM, Rowson J, Wynford-Thomas D, Kipling D. 2003. Extensive allelic variation and ultrashort telomeres in senescent human cells. Nat Genet 33: 203-207.

Baumann P, Cech TR. 2001. Pot1, the putative telomere endbinding protein in fission yeast and humans. Science 292: 1171-5.

Briggs TA, Abdel-Salam GM, Balicki M, Baxter P, Bertini E, Bishop N, Browne BH, Chitayat D, Chong WK, Eid MM, et al. 2008. Cerebroretinal microangiopathy with calcifications and cysts (CRMCC). Am I Med Genet A 146A: 182-190.

Bryan C, Rice C, Harkisheimer M, Schultz DC, Skordalakes E. 2013. Structure of the human telomeric Stn1-Ten1 capping complex. PLoS One 8: e66756.

Carr IM, Flintoff KJ, Taylor GR, Markham AF, Bonthron DT. 2006. Interactive visual analysis of SNP data for rapid autozygosity mapping in consanguineous families. Hum Mutat 27: 1041-1046.

Casteel DE, Zhuang S, Zeng Y, Perrino FW, Boss GR, Goulian M, Pilz RB. 2009. A DNA polymerase- $\alpha$-primase cofactor with homology to replication protein A-32 regulates DNA replication in mammalian cells. J Biol Chem 284: 5807-5818.

Celli GB, de Lange T. 2005. DNA processing is not required for ATM-mediated telomere damage response after TRF2 deletion. Nat Cell Biol 7: 712-718.

Chen LY, Lingner J. 2013. CST for the grand finale of telomere replication. Nucleus 4: 277-282.

Chen LY, Redon S, Lingner J. 2012. The human CST complex is a terminator of telomerase activity. Nature 488: 540-544.

Chen LY, Majerska J, Lingner J. 2013. Molecular basis of telomere syndrome caused by CTC1 mutations. Genes Dev 27: 20992108.

Crow YJ, McMenamin J, Haenggeli CA, Hadley DM, Tirupathi S, Treacy EP, Zuberi SM, Browne BH, Tolmie JL, Stephenson JB. 2004. Coats' plus: a progressive familial syndrome of bilateral Coats' disease, characteristic cerebral calcification, leukoencephalopathy, slow pre- and post-natal linear growth and defects of bone marrow and integument. Neuropediatrics 35: 10-19. 
Diotti R, Kalan S, Matveyenko A, Loayza D. 2014. DNA-directed polymerase subunits play a vital role in human telomeric overhang processing. Mol Cancer Res 13: 402-410.

Gao H, Cervantes RB, Mandell EK, Otero JH, Lundblad V. 2007. RPA-like proteins mediate yeast telomere function. Nat Struct Mol Biol 14: 208-214.

Garvik B, Carson M, Hartwell L. 1995. Single-stranded DNA arising at telomeres in cdc13 mutants may constitute a specific signal for the RAD9 checkpoint. Mol Cell Biol 15: 6128-6138.

Goulian M, Heard CJ, Grimm SL. 1990. Purification and properties of an accessory protein for DNA polymerase $\alpha /$ primase. J Biol Chem 265: 13221-13230.

Grandin N, Reed SI, Charbonneau M. 1997. Stn1, a new Saccharomyces cerevisiae protein, is implicated in telomere size regulation in association with Cdc13. Genes Dev 11: 512-27.

Grossi S, Puglisi A, Dmitriev PV, Lopes M, Shore D. 2004. Pol12, the B subunit of DNA polymerase $\alpha$, functions in both telomere capping and length regulation. Genes Dev 18: 992-1006.

Gu P, Min JN, Wang Y, Huang C, Peng T, Chai W, Chang S. 2012. CTC1 deletion results in defective telomere replication, leading to catastrophic telomere loss and stem cell exhaustion. EMBO J 31: 2309-2321.

He H, Wang Y, Guo X, Ramchandani S, Ma J, Shen MF, Garcia DA, Deng Y, Multani AS, You MJ, et al. 2009. Pot1b deletion and telomerase haploinsufficiency in mice initiate an ATRdependent DNA damage response and elicit phenotypes resembling dyskeratosis congenita. Mol Cell Biol 29: 229-240.

Hemann MT, Greider CW. 1999. G-strand overhangs on telomeres in telomerase-deficient mouse cells. Nucleic Acids Res 27: 3964-3969.

Hockemeyer D, Sfeir AJ, Shay JW, Wright WE, de Lange T. 2005. POT1 protects telomeres from a transient DNA damage response and determines how human chromosomes end. EMBO I 24: 2667-2678.

Hockemeyer D, Daniels JP, Takai H, de Lange T. 2006. Recent expansion of the telomeric complex in rodents: two distinct POT1 proteins protect mouse telomeres. Cell 126: 63-77.

Hockemeyer D, Palm W, Else T, Daniels JP, Takai KK, Ye JZ, Keegan CE, de Lange T, Hammer GD. 2007. Telomere protection by mammalian POT1 requires interaction with TPP1. Nat Struct Mol Biol 14: 754-761.

Hockemeyer D, Palm W, Wang RC, Couto SS, de Lange T. 2008. Engineered telomere degradation models dyskeratosis congenita. Genes Dev 22: 1773-1785.

Jackson EL, Willis N, Mercer K, Bronson RT, Crowley D, Montoya R, Jacks T, Tuveson DA. 2001. Analysis of lung tumor initiation and progression using conditional expression of oncogenic K-ras. Genes Dev 15: 3243-3248.

Kabir S, Hockemeyer D, de Lange T. 2014. TALEN gene knockouts reveal no requirement for the conserved human shelterin protein Rap1 in telomere protection and length regulation. Cell Rep 9: 1273-1280.

Kasbek C, Wang F, Price CM. 2013. Human TEN1 maintains telomere integrity and functions in genome-wide replication restart. J Biol Chem 288: 30139-30150.

Kelleher C, Kurth I, Lingner J. 2005. Human protection of telomeres 1 (POT1) is a negative regulator of telomerase activity in vitro. Mol Cell Biol 25: 808-818.

Lei M, Podell ER, Cech TR. 2004. Structure of human POT1 bound to telomeric single-stranded DNA provides a model for chromosome end-protection. Nat Struct Mol Biol 11: 1223-1229.

Lenain C, Bauwens S, Amiard S, Brunori M, Giraud-Panis MJ, Gilson E. 2006. The Apollo 5' exonuclease functions together with TRF2 to protect telomeres from DNA repair. Curr Biol 16: $1303-1310$.

Lin TT, Norris K, Heppel NH, Pratt G, Allan JM, Allsup DJ, Bailey J, Cawkwell L, Hills R, Grimstead JW, et al. 2014. Telomere dysfunction accurately predicts clinical outcome in chronic lymphocytic leukaemia, even in patients with early stage disease. Br J Haematol 167: 214-223.

Linnankivi T, Valanne L, Paetau A, Alafuzoff I, Hakumäki JM, Kivelä T, Lönnqvist T, Mäkitie O, Pääkkönen L, Vainionpää L, et al. 2006. Cerebroretinal microangiopathy with calcifications and cysts. Neurology 67: 1437-1443.

Liu D, Safari A, O'Connor MS, Chan DW, Laegeler A, Qin J, Songyang Z. 2004. PTOP interacts with POT1 and regulates its localization to telomeres. Nat Cell Biol 6: 673-680.

Loayza D, de Lange T. 2003. POT1 as a terminal transducer of TRF1 telomere length control. Nature 424: 1013-1018.

Martin V, Du LL, Rozenzhak S, Russell P. 2007. Protection of telomeres by a conserved Stn1-Ten1 complex. Proc Nat1 Acad Sci 104: 14038-14043.

Martínez P, Thanasoula M, Muñoz P, Liao C, Tejera A, McNees C, Flores JM, Fernández-Capetillo $\mathrm{O}$, Tarsounas $\mathrm{M}$, Blasco MA. 2009. Increased telomere fragility and fusions resulting from TRF1 deficiency lead to degenerative pathologies and increased cancer in mice. Genes Dev 23: 2060-2075.

Martinez P, Thanasoula M, Carlos AR, Gómez-López G, Tejera AM, Schoeftner S, Dominguez O, Pisano DG, Tarsounas M, Blasco MA. 2010. Mammalian Rap1 controls telomere function and gene expression through binding to telomeric and extratelomeric sites. Nat Cell Biol 12: 768-780.

Miyake Y, Nakamura M, Nabetani A, Shimamura S, Tamura M, Yonehara S, Saito M, Ishikawa F. 2009. RPA-like mammalian Ctc1-Stn1-Ten1 complex binds to single-stranded DNA and protects telomeres independently of the Pot1 pathway. Mol Cell 36: 193-206.

Myler LR, Gallardo IF, Zhou Y, Gong F, Yang SH, Wold MS, Miller KM, Paull TT, Finkelstein IJ. 2016. Single-molecule imaging reveals the mechanism of Exol regulation by singlestranded DNA binding proteins. Proc Natl Acad Sci 113: E1170-E1179.

Nakamura M, Nabetani A, Mizuno T, Hanaoka F, Ishikawa F. 2005. Alterations of DNA and chromatin structures at telomeres and genetic instability in mouse cells defective in DNA polymerase a. Mol Cell Biol 25: 11073-11088.

Nakaoka H, Nishiyama A, Saito M, Ishikawa F. 2012. Xenopus laevis Ctc1-Stn1-Ten1 (xCST) protein complex is involved in priming DNA synthesis on single-stranded DNA template in Xenopus egg extract. J Biol Chem 287: 619-627.

Nimonkar AV, Genschel J, Kinoshita E, Polaczek P, Campbell JL, Wyman C, Modrich P, Kowalczykowski SC. 2011. BLMDNA2-RPA-MRN and EXO1-BLM-RPA-MRN constitute two DNA end resection machineries for human DNA break repair. Genes Dev 25: 350-362.

Palm W, de Lange T. 2008. How shelterin protects mammalian telomeres. Annu Rev Genet 42: 301-334.

Pascolo E, Wenz C, Lingner J, Hauel N, Priepke H, Kauffmann I, Garin-Chesa P, Rettig WJ, Damm K, Schnapp A. 2002. Mechanism of human telomerase inhibition by BIBR1532, a synthetic, non-nucleosidic drug candidate. I Biol Chem 277: 15566-15572.

Polvi A, Linnankivi T, Kivelä T, Herva R, Keating JP, Mäkitie O, Pareyson D, Vainionpää L, Lahtinen J, Hovatta I, et al. 2012. Mutations in CTC1, encoding the CTS telomere maintenance complex component 1 , cause cerebroretinal microangiopathy with calcifications and cysts. Am J Hum Genet 90: 540-549. 
Takai et al.

Price CM, Boltz KA, Chaiken MF, Stewart JA, Beilstein MA, Shippen DE. 2010. Evolution of CST function in telomere maintenance. Cell Cycle 9: 3157-3165.

Qi H, Zakian VA. 2000. The Saccharomyces telomere-binding protein Cdc13p interacts with both the catalytic subunit of DNA polymerase $a$ and the telomerase- associated est 1 protein. Genes Dev 14: 1777-1788.

Reyon D, Tsai SQ, Khayter C, Foden JA, Sander JD, Joung JK. 2012. FLASH assembly of TALENs for high-throughput genome editing. Nat Biotechnol 30: 460-465.

Savage SA, Bertuch AA. 2010. The genetics and clinical manifestations of telomere biology disorders. Genet Med 12: 753-764.

Sfeir AJ, Chai W, Shay JW, Wright WE. 2005. Telomere-end processing the terminal nucleotides of human chromosomes. Mol Cell 18: 131-138.

Sfeir A, Kosiyatrakul ST, Hockemeyer D, MacRae SL, Karlseder J, Schildkraut CL, de Lange T. 2009. Mammalian telomeres resemble fragile sites and require TRF1 for efficient replication. Cell 138: 90-103.

Song X, Leehy K, Warrington RT, Lamb JC, Surovtseva YV, Shippen DE. 2008. STN1 protects chromosome ends in Arabidopsis thaliana. Proc Natl Acad Sci 105: 19815-19820.

Stewart JA, Wang F, Chaiken MF, Kasbek C, Chastain PD, Wright WE, Price CM. 2012. Human CST promotes telomere duplex replication and general replication restart after fork stalling. EMBO J 31: 3537-3549.

Surovtseva YV, Churikov D, Boltz KA, Song X, Lamb JC, Warrington R, Leehy K, Heacock M, Price CM, Shippen DE. 2009. Conserved telomere maintenance component 1 interacts with STN1 and maintains chromosome ends in higher eukaryotes. Mol Cell 36: 207-218.

Takai H, Smogorzewska A, de Lange T. 2003. DNA damage foci at dysfunctional telomeres. Curr Biol 13: 1549-1556.

Takai KK, Hooper S, Blackwood S, Gandhi R, de Lange T. 2010. In vivo stoichiometry of shelterin components. J Biol Chem 285: 1457-1467.

Toledo LI, Murga M, Zur R, Soria R, Rodriguez A, Martinez S, Oyarzabal J, Pastor J, Bischoff JR, Fernandez-Capetillo O. 2011. A cell-based screen identifies ATR inhibitors with syn- thetic lethal properties for cancer-associated mutations. Nat Struct Mol Biol 18: 721-727.

Tolmie JL, Browne BH, McGettrick PM, Stephenson JB. 1988. A familial syndrome with coats' reaction retinal angiomas, hair and nail defects and intracranial calcification. Eye (Lond) 2: 297-303.

Untergasser A, Cutcutache I, Koressaar T, Ye J, Faircloth BC, Remm M, Rozen SG. 2012. Primer3-new capabilities and interfaces. Nucleic Acids Res 40: e115.

Walne AJ, Bhagat T, Kirwan M, Gitiaux C, Desguerre I, Leonard N, Nogales E, Vulliamy T, Dokal IS. 2013. Mutations in the telomere capping complex in bone marrow failure and related syndromes. Haematologica 98: 334-338.

Wan M, Qin J, Songyang Z, Liu D. 2009. OB fold-containing protein 1 (OBFC1), a human homolog of yeast Stn1, associates with TPP1 and is implicated in telomere length regulation. $J$ Biol Chem 284: 26725-26731.

Wang F, Stewart JA, Kasbek C, Zhao Y, Wright WE, Price CM. 2012. Human CST has independent functions during telomere duplex replication and C-strand fill-in. Cell Rep 2: 1096-1103.

Weinert TA, Hartwell LH. 1993. Cell cycle arrest of cdc mutants and specificity of the RAD9 checkpoint. Genetics 134: 63-80.

Wu P, van Overbeek M, Rooney S, de Lange T. 2010. Apollo contributes to $\mathrm{G}$ overhang maintenance and protects leading-end telomeres. Mol Cell 39: 1-12.

Wu P, Takai H, de Lange T. 2012. Telomeric 3' overhangs derive from resection by Exol and Apollo and fill-in by POT1b-associated CST. Cell 150: 39-52.

Ye JZ, Hockemeyer D, Krutchinsky AN, Loayza D, Hooper SM, Chait BT, de Lange T. 2004. POT1-interacting protein PIP1: a telomere length regulator that recruits POT1 to the TIN2/ TRF1 complex. Genes Dev 18: 1649-1654.

Zimmermann M, Kibe T, Kabir S, de Lange T. 2014. TRF1 negotiates TTAGGG repeat-associated replication problems by recruiting the BLM helicase and the TPP1/POT1 repressor of ATR signaling. Genes Dev 28: 2477-2491.

Zubko MK, Guillard S, Lydall D. 2004. Exo1 and Rad24 differentially regulate generation of ssDNA at telomeres of Saccharomyces cerevisiae cdc13-1 mutants. Genetics 168: 103-115. 


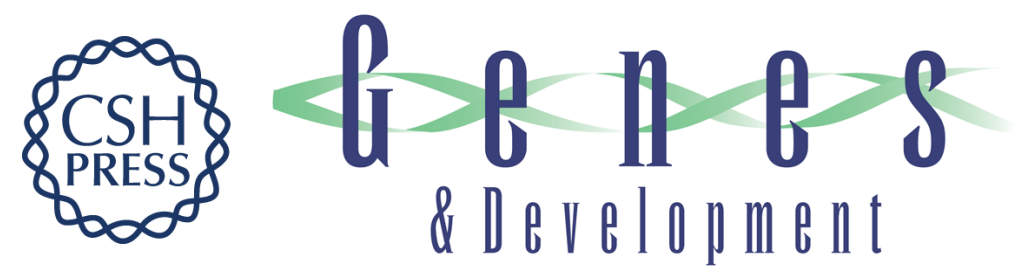

\section{A POT1 mutation implicates defective telomere end fill-in and telomere truncations in Coats plus}

Hiroyuki Takai, Emma Jenkinson, Shaheen Kabir, et al.

Genes Dev. 2016, 30: originally published online March 24, 2016

Access the most recent version at doi:10.1101/gad.276873.115

\section{Supplemental http://genesdev.cshlp.org/content/suppl/2016/03/22/gad.276873.115.DC1 Material}

References This article cites 69 articles, 31 of which can be accessed free at: http://genesdev.cshlp.org/content/30/7/812.full.html\#ref-list-1

Creative This article is distributed exclusively by Cold Spring Harbor Laboratory Press for the first Commons six months after the full-issue publication date (see

License http://genesdev.cshlp.org/site/misc/terms.xhtml). After six months, it is available under a Creative Commons License (Attribution-NonCommercial 4.0 International), as described at http://creativecommons.org/licenses/by-nc/4.0/.

Email Alerting Receive free email alerts when new articles cite this article - sign up in the box at the top Service right corner of the article or click here.

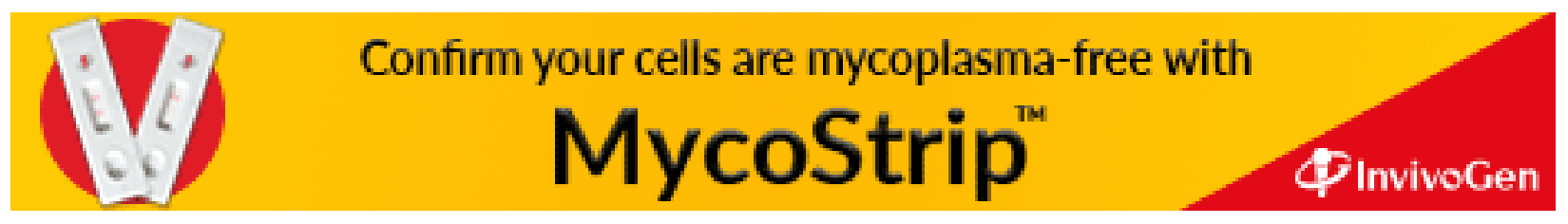

